\title{
Lr34-Mediated Leaf Rust Resistance in Wheat: Transcript Profiling Reveals a High Energetic Demand Supported by Transient Recruitment of Multiple Metabolic Pathways
}

\author{
Melvin D. Bolton, ${ }^{1}$ James A. Kolmer, ${ }^{2}$ Wayne W. Xu, ${ }^{3}$ and David F. Garvin ${ }^{1}$ \\ ${ }^{1}$ United States Department of Agriculture-Agricultural Research Service (USDA-ARS), Plant Science Research Unit, \\ 411 Borlaug Hall, University of Minnesota, 1991 Upper Buford Circle, St. Paul 55108, U.S.A.; ${ }^{2}$ USDA-ARS, \\ Cereal Disease Laboratory, 1551 Lindig St., University of Minnesota, St. Paul 55108, U.S.A.; ${ }^{3}$ Supercomputing Institute, \\ 550 Walter Library, 117 Pleasant Street SE, University of Minnesota, Minneapolis 55455, U.S.A.
}

Submitted 19 June 2008. Accepted 18 August 2008.

\begin{abstract}
The wheat gene Lr34 confers partial resistance to all races of Puccinia triticina, the causal agent of wheat leaf rust. However, the biological basis for the exceptional durability of Lr34 is unclear. We used the Affymetrix GeneChip Wheat Genome Array to compare transcriptional changes of near-isogenic lines of Thatcher wheat in a compatible interaction, an incompatible interaction conferred by the resistance gene $L r 1$, and the race-nonspecific response conditioned by $L r 343$ and 7 days postinoculation (dpi) with $P$. triticina. No differentially expressed genes were detected in $\mathrm{Lr} 1$ plants at either timepoint whereas, in the compatible Thatcher interaction, differentially expressed genes were detected only at 7 dpi. In contrast, differentially expressed genes were identified at both timepoints in P. triticina-inoculated Lr34 plants. At 3 dpi, upregulated genes associated with Lr34-mediated resistance encoded various defense and stress-related proteins, secondary metabolism enzymes, and transcriptional regulation and cellular-signaling proteins. Further, coordinated upregulation of key genes in several metabolic pathways that can contribute to increased carbon flux through the tricarboxylic cycle was detected. This indicates that Lr34-mediated resistance imposes a high energetic demand that leads to the induction of multiple metabolic responses to support cellular energy requirements. These metabolic responses were not sustained through $7 \mathrm{dpi}$, and may explain why Lr34 fails to inhibit the pathogen fully but does increase the latent period.
\end{abstract}

Corresponding author: David F. Garvin; Telephone: +1.612.625.1975; Fax: +1.651.649.5058; E-mail: David.Garvin@ars.usda.gov

Current address of M. D. Bolton: United States Department of AgricultureAgricultural Research Service, Northern Crops Science Laboratory, Fargo, ND 58105-5677, U.S.A.

Microarray data are deposited in the National Center for Biotechnology Information Gene Expression Omnibus under the accession GSE9915.

* The $\boldsymbol{e}$-Xtra logo stands for "electronic extra" and indicates that three supplementary tables are published online.

This article is in the public domain and not copyrightable. It may be freely reprinted with customary crediting of the source. The American Phytopathological Society, 2008.
Additional keywords: $\beta$-oxidation, GABA, gene expression, glycolysis, PDH bypass, TCA cycle.

The biotrophic fungus Puccinia triticina Erikss. is the causal agent of leaf rust of wheat (Triticum aestivum L.) (Bolton et al. 2008). Leaf rust occurs nearly wherever wheat is grown, resulting in yield losses and reduced grain quality. High levels of pathogenic variation and adaptability to diverse climatic conditions are hallmarks of $P$. triticina and contribute to its persistence as a major pathogen of wheat (Kolmer 2005; Ordoñez and Kolmer 2007; Webb and Fellers 2006). Host resistance is the preferred method to reduce losses from leaf rust, and more than 50 leaf rust resistance $(L r)$ genes have been identified in wheat (Integrated Wheat Science database). Most $L r$ genes confer race-specific resistance in a gene-for-gene manner. Such $L r$ genes condition an incompatible interaction when they interact with $P$. triticina avirulence $(A v r)$ gene products. This incompatible interaction is characterized by a hypersensitive cell death response (HR) and the induction of defenserelated genes that halt pathogen growth. The race-specific leaf rust resistance genes $\operatorname{Lrl}, \mathrm{Lr} 10$, and $\operatorname{Lr} 21$ have been cloned, and exhibit classical features of plant disease resistance $(R)$ genes, including nucleotide-binding site (NBS) and leucinerich repeat (LRR) coding regions (Cloutier et al. 2007; Feuillet et al. 2003; Huang et al. 2003).

Many race-specific $L r$ genes are no longer useful because they have been overcome by virulent races of the pathogen. Thus, wheat breeders are beginning to focus more on the use of race-nonspecific resistance genes. Race-nonspecific resistance to leaf rust is characterized by a partial resistance phenotype expressed in adult plants (Kolmer 2005; McIntosh et al. 1995). Combined with race-specific $L r$ genes, race-nonspecific resistance genes can condition long-lasting, effective leaf rust resistance (Kolmer and Oelke 2006; Oelke and Kolmer 2005).

The most important race-nonspecific resistance leaf rust resistance gene in wheat is Lr34 (Dyck 1987; Dyck et al. 1966). This gene is found in wheat grown around the world and has provided durable resistance for several decades (Dyck 1991, 1994). Lr34 is associated with a reduced rate of haustorium formation in early stages of infection and reduced intercellular hyphal growth (Rubiales and Niks 1995). The resistance phenotype of Lr34 is characterized by an increased latent period, reduced infection frequency, smaller uredinia, and a 
decreasing gradient of uredinia from leaf base to tip (Drijepondt and Pretorius 1989; Rubiales and Niks 1995; Singh and Huerta-Espino 2003). Resistance is also more pronounced at temperatures below $25^{\circ} \mathrm{C}$ (Singh and Gupta 1992). Lr34 is associated with the gene Ltn that confers leaf tip necrosis that progresses from the leaf tip toward the base in flag leaves over time (Singh 1992a). In addition to improved leaf rust resistance, lines containing Lr34 also exhibit enhanced resistance to both stripe rust and stem rust, possess adult plant resistance to powdery mildew caused by Blumeria graminis f. sp. tritici, and show improved tolerance to Barley yellow dwarf virus (Kolmer 1996; Singh 1992b; Singh 1993; Spielmeyer et al. 2005). Therefore, Lr34 is useful for improving resistance to multiple diseases and is a model gene for understanding the biological basis of race-nonspecific resistance.

Although Lr34 has been used extensively in wheat improvement, little is known about the molecular basis of Lr34-mediated resistance. Because Lr34 slows but does not stop pathogen
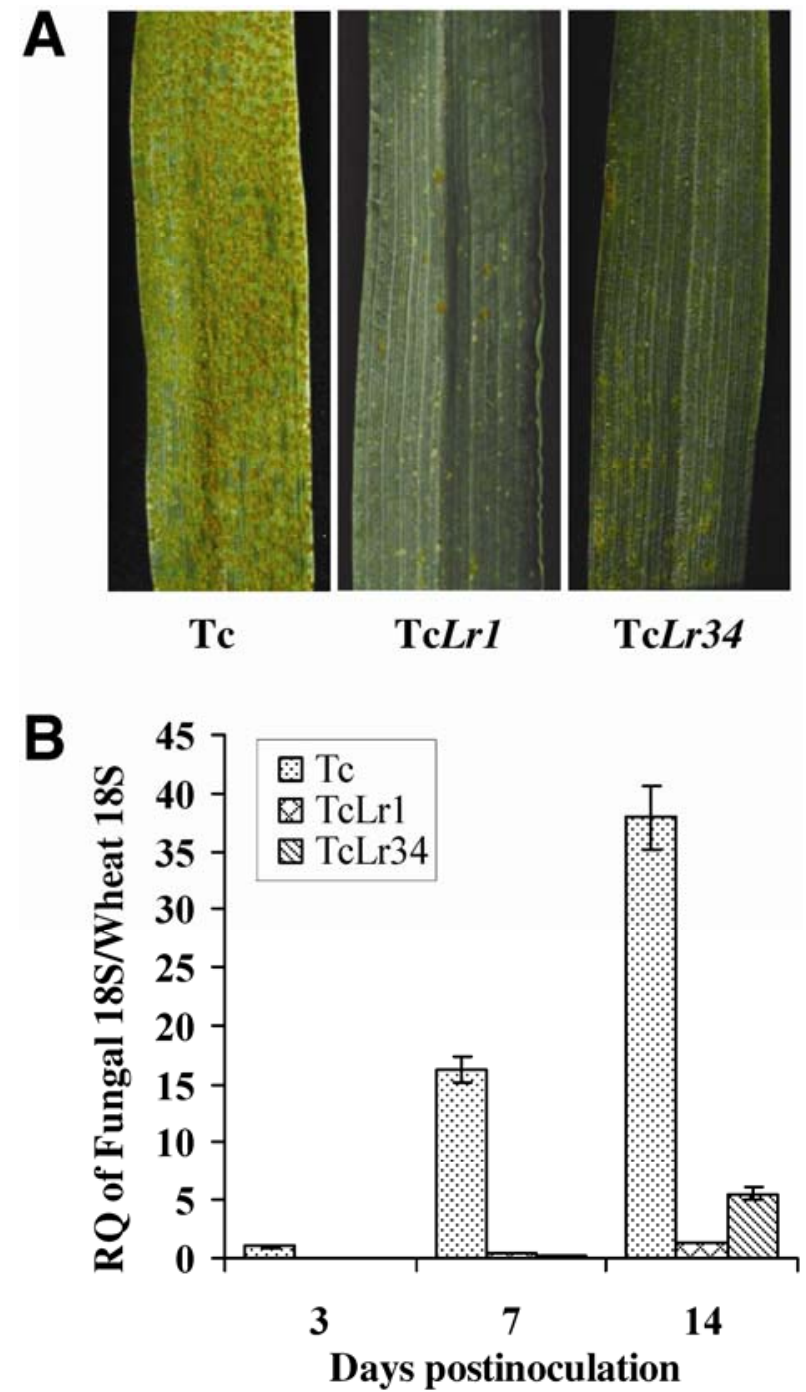

Fig. 1. Disease development of Puccinia triticina race 1 on wheat nearisolines. A, Typical symptoms on the susceptible wheat cv. Thatcher (Tc), on a Tc near-isoline with the R-gene $L r l$ (TcLrl), and on a Tc near-isoline with Lr34 (TcLr34) 14 days after inoculation (dpi). Leaf images display $4.5 \mathrm{~cm}$ of length starting $1 \mathrm{~cm}$ from the leaf base (at bottom). B, Quantitative real-time reverse-transcription polymerase chain reaction determination of fungal load of $P$. triticina on inoculated Tc, TcLrl, and TcLr34 at 3,7 , and $14 \mathrm{dpi}$, determined by relative quantification (RQ) of P. triticina $18 \mathrm{~S}$ rRNA gene abundance to wheat $18 \mathrm{~S}$ rRNA gene abundance. Bars represent standard errors of three technical replicates. growth, its resistance phenotype is reminiscent of plant basal resistance arising from recognition of general elicitor or pathogen-associated molecular patterns (PAMPs) such as bacterial flagellin or cell wall constituents (Ausubel 2005; Nürnberger et al. 2004). PAMP recognition is achieved through transmembrane pattern recognition receptors which induce mitogen-activated protein (MAP) kinase signaling cascades and a suite of basal defense responses sufficient to stop or slow growth of both nonpathogenic and pathogenic microbes (Dangl 2007; Jones and Dangl 2006). However, pathogenic microbes can secrete effector molecules to suppress this basal defense response, leading to their establishment (Abramovitch and Martin 2004; Caldo et al. 2006; Kim et al. 2005). In Lr34-mediated defense against $P$. triticina, it is not clear whether the eventual growth of the pathogen is due to successful pathogen suppression of host basal defense targets or if there is a gradual attenuation of the defense response in Lr34-mediated resistance.

The regulation of gene expression, including both temporal aspects and magnitude of gene expression changes, is one factor that determines susceptibility or resistance in the host plant (Caldo et al. 2004, 2006; Kong et al. 2005; Kruger et al. 2003). To test the hypothesis that the molecular basis of Lr34-mediated resistance differs from HR-mediated resistance, we employed $L r$ near-isogenic lines of the spring wheat $\mathrm{cv}$. Thatcher in combination with Affymetrix GeneChip Wheat Genome Arrays to compare transcriptional changes associated with i) a compatible interaction between wheat and P. triticina, ii) leaf rust resistance encoded by a race-specific resistance gene, and iii) race-nonspecific resistance provided by $L r 34$, at two timepoints representing distinct stages of $P$. triticina infection. Our results indicate that the resistance response conditioned by Lr34 is different than that associated with Lrl. The Lr34 resistance response is active, based upon increased expression of a variety of defense-related genes. Further, this response has an extremely high energetic demand, as inferred from transient induction of genes in multiple metabolic pathways, including the tricarboxylic acid (TCA) cycle, glycolysis, the pyruvate dehydrogenase (PDH) bypass, $\beta$-oxidation, the GABA shunt, and CoA biosynthesis. Upregulation of these pathways provides a means for cells to maintain carbon flux through primary metabolism when normal levels of respiration are inadequate to maintain cellular energy demand.

\section{RESULTS}

\section{Quantification of $P$. triticina biomass in infected wheat leaves.}

Race 1 (BBB) of $P$. triticina was used to compare pathogen development in i) a compatible leaf rust interaction using the wheat cv. Thatcher (Tc); ii) an $R$-gene-mediated, race-specific incompatible interaction using a Thatcher near-isoline with Lrl (TcLrl); and iii) a race-nonspecific interaction using a Thatcher near-isoline with Lr34 (TcLr34). Inoculated flag leaves were harvested at 3, 7, and 14 days postinoculation (dpi) for experiments. In the compatible interaction between $P$. triticina and Tc, the fungus penetrated through stomata and formed haustoria to obtain nutrients from the susceptible host. At $7 \mathrm{dpi}$, the first uredinia were detected and, by $14 \mathrm{dpi}$, significant numbers of large uredinia were evident (Fig. 1A). In the incompatible interaction conditioned by $\mathrm{Lrl}$, no disease symptoms were evident save for a few uredinia per inoculated leaf (Fig. 1A). These uredinia are representative of a very minor frequency of non-race 1 spores present in the spore suspension used for inoculation that are not recognized by Lrl and, therefore, can proliferate in TcLrl. In contrast to the compatible interaction, the partial resistance associated with Lr34 is characterized by a latent period which, in this study, delayed 
uredinia formation until 14 dpi. At this timepoint, small numbers of pustules began appearing on TcLr34 plants but were confined to the basal regions of the leaves. (Fig. 1A).

Quantitative real-time reverse-transcription polymerase chain reaction (qPCR) with separate primer pairs for either wheat or fungal $18 \mathrm{~S}$ rRNA genes was employed to estimate fungal biomass relative to plant biomass at the three timepoints. PCR primers are listed in Supplementary Table 1. In the compatible Tc interaction, fungal biomass increased steadily as the disease progressed, whereas little fungal biomass accumulation was found in TcLrl (Fig. 1B). In TcLr34, biomass slowly increased over time (Fig. 1B), consistent with the expected increased latent period associated with $\operatorname{Lr} 34$.

\section{Wheat gene expression changes during $P$. triticina infection.}

The Affymetrix GeneChip Wheat Genome Array was used to identify wheat genes differentially expressed in Tc, TcLrl, and TcLr34 in response to challenge by $P$. triticina race 1. Transcriptome interrogation was conducted on leaves harvested at 3 and 7 dpi. The first timepoint was selected to characterize a point in infection at which differences between the genotypes Tc and TcLrl were expected to be found, thus providing a gene expression footprint representative of the HR at this timepoint. The timepoint of $7 \mathrm{dpi}$ was chosen because it was the day at which uredinia first appeared on inoculated $\mathrm{Tc}$ leaves.

Leaf tip necrosis is a phenotype that is coincident with $\operatorname{Lr} 34$, affects a significant portion of the flag leaf, and progresses over time (Spielmeyer et al. 2005). We assumed that leaf tip necrosis would generate gene expression differences that would be difficult to differentiate from those differences associated with the response to $P$. triticina in which we were interested. Indeed, an initial Student's $t$ test comparison between mock-inoculated TcLr34 and mock-inoculated Tc at 3 and 7 dpi ( $P$ value $\leq 0.001$, fold-regulation cut-off of $\geq 2.0$ ) identified 65 and 160 differentially expressed probe sets at 3 and 7 dpi, respectively (data not shown). Because we sought to identify gene expression differences solely associated with the response to $P$. triticina infection and because some treatmenttimepoint-genotype comparisons (e.g., Tc mock inoculated at 3 dpi versus Tc mock inoculated at $7 \mathrm{dpi}$ ) were not germane to our study, we employed univariate analysis ( $t$ tests, $P$ value $\leq$ 0.001 , fold-regulation difference $\geq 2.0$ ) between mock- and $P$. triticina-inoculated plants for each genotype at each timepoint, resulting in six pairwise gene expression comparisons with GeneChip data. Tissue was sampled at the same time of each of the 2 days; therefore, gene expression changes associated with diurnal rhythms were avoided.

Differential gene expression 3 dpi. We identified 151 genes that were differentially expressed between mock and pathogen treatments at 3 dpi in TcLr34 (Table 1). Genes identified by initial $t$ tests were associated with a false discovery rate (FDR) of approximately $8 \%$ and contained 129 upregulated and 5 downregulated genes. An additional 17 genes were called present in P. triticina-inoculated TcLr34 and absent in the comparable mock-inoculated controls, with an associated FDR of $18 \%$ (Table 2). Using the same statistical criteria, we identified no differentially expressed genes in either Tc or TcLrl inoculated with $P$. triticina at $3 \mathrm{dpi}$ compared with their respective mock-inoculated controls.

Differential expression 7 dpi. In all, 132 genes exhibited differential expression between mock- and pathogen-treated TcLr34 at 7 dpi (Supplementary Table 2). This set of genes was associated with an FDR of approximately 7\%, and contained 123 genes upregulated in TcLr34 and 2 that were downregulated, with the present/absent search function identifying an additional 7 genes present in the $P$. triticina-inoculated TcLr34 plants with an FDR of approximately 14\% (Table 2). As for the 3 dpi timepoint, we identified no differentially expressed genes in TcLrl. In contrast to the 3 dpi results, we identified 166 differentially expressed genes in the compatible Tc-P. triticina interaction (Supplementary Table 3, FDR 4\%), with the present/absent search function identifying 15 genes called present in pathogen-inoculated Tc and absent in the relevant mocks, with an FDR of $8 \%$ (Table 2). In total, just 26 differentially expressed genes overlapped in two or more of the experiments (Fig. 2).

\section{Comparison of real-time PCR versus \\ GeneChip-based quantitative gene expression differences.}

qPCR was used to compare quantitative gene expression differences obtained from GeneChips to those from an alternative quantitation method. Fifteen genes were chosen for validation purposes. Of the 15 genes, 7 were used at both timepoints. These genes represent a wide range of $P$ value and fold-regulation differences in the microarray analysis and represent genes with diverse functions. Total RNA pooled across the same biological replicates used for microarray analysis was used for qPCR analysis. Quantification of gene expression was performed using the comparative cycle threshold $\left(\mathrm{C}_{\mathrm{T}}\right)$ method $\left(\Delta \Delta \mathrm{C}_{\mathrm{T}}\right)$. The qPCR results were highly concordant with microarray results, with an $R^{2}$ value of 0.96 and a slope of 0.983 . (Fig. 3).

\section{Classification of pathogen-responsive wheat genes.}

Putative functions were assigned to 372 of the 450 differentially expressed genes identified in experiments based on best BlastX hits ( $e$ value threshold $\leq 10^{-10}$ ) provided by HarvEST. Gene ontology (GO) terms for biological and molecular function (Ashburner et al. 2000) were obtained by querying the UniProt Protein Knowledgebase with protein IDs from HarvEST. Genes were then assigned to generic functional classes (metabolism/structure/maintenance, defense/stress, signaling, transcription, transport, or unclassified). When $e$ values were greater than the BlastX threshold, genes were listed as "no annotation available."

Pathogen-responsive genes in Tc. Gene expression differences were detected in Tc only at $7 \mathrm{dpi}$. Approximately onethird of these 166 genes were downregulated in the pathogen treatment. Differentially expressed genes relating to cell metabolism had diverse functions in over 20 biological processes. Certain genes encoding proteins involved in amino acid synthesis and metabolism were differentially expressed. For example, the gene encoding acetolactate synthase, the first committed enzymatic step in the biosynthetic pathway leading to leucine, isoleucine, and valine synthesis (Singh and Shaner 1995), was highly (71-fold) upregulated. In contrast, a gene encoding shikimate kinase, an enzyme of the shikimate pathway leading to aromatic amino acid production (Herrmann and Weaver 1999), was downregulated twofold. The gene encoding nicotianamine (NA) aminotransferase, which converts NA to mugineic acid, a nonprotein amino acid phytometallophore induced during Fe deficiency (Shojima et al. 1990), was upregulated 5.9-fold.

Several genes upregulated at $7 \mathrm{dpi}$ in the compatible Tc- $P$. triticina interaction encoded steps of the glyoxylate cycle, a five-reaction pathway which mediates the conversion of acetylCoA to oxaloacetate (Tolbert 1981). Genes encoding glyoxysomal citrate synthase (upregulated 2.4-fold) and isocitrate lyase (upregulated 77-fold) were differentially expressed. In addition, the gene encoding alanine:glyoxylate aminotransferase 2 was upregulated ( 4.8 -fold). This enzyme catalyzes the reversible conversion of alanine and glyoxylate to glycine and 
Table 1. Predicted functions of 151 genes differentially expressed in the comparison of mock- and Puccinia triticina-inoculated TcLr34 at 3 days postinoculation

\begin{tabular}{|c|c|c|c|c|c|}
\hline Probe set ID & Predicted function $^{\mathrm{a}}$ & E value & $P$ value $^{\mathrm{b}}$ & $q$ value $^{c}$ & Fold change $^{d}$ \\
\hline \multicolumn{6}{|l|}{ General cellular ${ }^{\mathrm{e}}$} \\
\hline Ta.968.1.S1_at & $\alpha$-Ketoglutarate dehydrogenase & $6 \mathrm{E}-93$ & 0.00035 & 0.126 & 2.57 \\
\hline TaAffx.21249.1.S1_at & 41-kDa chloroplast nucleoid DNA binding protein & $2 \mathrm{E}-83$ & 0.00001 & 0.038 & 2.48 \\
\hline TaAffx.110726.1.S1_s_at & 41-kDa chloroplast nucleoid DNA binding protein & $2 \mathrm{E}-40$ & 0.00024 & 0.051 & 6.84 \\
\hline TaAffx.56014.2.S1_x_at & 41-kDa chloroplast nucleoid DNA binding protein & $5 \mathrm{E}-25$ & 0.00005 & 0.048 & 9.27 \\
\hline TaAffx.8265.1.S1_at & 6-Phosphofructokinase & $4 \mathrm{E}-80$ & 0.00017 & 0.048 & 2.13 \\
\hline TaAffx.42772.1.A1]_at & Acyltransferase & $6 \mathrm{E}-61$ & 0.00065 & 0.073 & 2.06 \\
\hline Ta.2107.1.S1_s_at & Aldehyde dehydrogenase, family 7 member A1 & $1 \mathrm{E}-137$ & 0.00068 & 0.076 & 3.34 \\
\hline Ta.13949.1.A1_at & Amidase family protein & $1 \mathrm{E}-50$ & 0.00092 & 0.082 & 3.10 \\
\hline TaAffx.21593.1.S1_at & Aminotransferase-like protein & $1 \mathrm{E}-92$ & 0.00013 & 0.048 & 5.29 \\
\hline TaAffx.54526.1.S1_at & ATPase 2 & $2 \mathrm{E}-49$ & 0.00019 & 0.049 & 2.38 \\
\hline TaAffx.128683.1.S1_x_at & ATPase 3 & $3 \mathrm{E}-95$ & 0.00096 & 0.082 & 3.67 \\
\hline TaAffx.63502.1.S1_at & 4' Phosphopantetheine adenylyltransferase & $1.3 \mathrm{E}-57$ & 0.00012 & 0.048 & 2.43 \\
\hline Ta.4208.1.S1_a_at & Carboxypeptidase D & $1 \mathrm{E}-127$ & 0.00037 & 0.060 & 2.80 \\
\hline TaAffx.107485.1.S1_at & Cellulose synthase-like A1 & $8 \mathrm{E}-49$ & 0.00018 & 0.049 & 3.41 \\
\hline TaAffx.87259.1.S1_at & Cellulose synthase-like protein OsCslE1 & $8 \mathrm{E}-56$ & 0.00092 & 0.082 & 2.37 \\
\hline Ta.970.2.S1_a_at & Citrate synthase, glyoxysomal & $1 \mathrm{E}-125$ & 0.00013 & 0.048 & 2.30 \\
\hline Ta.8674.1.A1_at & Cycloartenol synthase & $4 \mathrm{E}-44$ & 0.00017 & 0.048 & 7.06 \\
\hline TaAffx.81099.1.S1_at & Cycloartenol synthase & $6 \mathrm{E}-42$ & 0.00057 & 0.069 & 9.22 \\
\hline Ta.7851.1.S1_at & Diphosphonucleotide phosphatase 1 & $1 \mathrm{E}-103$ & 0.00097 & 0.082 & 2.57 \\
\hline Ta.8639.1.S1_at & Diphosphonucleotide phosphatase 1 & $5 \mathrm{E}-97$ & 0.00070 & 0.076 & 3.23 \\
\hline TaAffx.52234.1.S1_at & Expansin EXPA10 & $6 \mathrm{E}-96$ & 0.00019 & 0.049 & -2.38 \\
\hline Ta.22579.1.S1_at & Glycosyltransferase & $1 \mathrm{E}-102$ & 0.00078 & 0.077 & 2.35 \\
\hline Ta.13974.1.A1_at & Glycosyltransferase & $5 \mathrm{E}-46$ & 0.00046 & 0.144 & 3.89 \\
\hline Ta.8773.1.S1_x_at & Growth regulator & $1 \mathrm{E}-100$ & 0.00006 & 0.048 & 2.26 \\
\hline Ta.3869.1.S1_at & Histidine amino acid transporter & $1 \mathrm{E}-102$ & 0.00027 & 0.055 & 3.19 \\
\hline Ta.27790.1.S1_s_at & Histone H1 WH1B.1 & $1 \mathrm{E}-148$ & 0.00003 & 0.047 & 3.10 \\
\hline Ta.12517.1.S1_at & Monosaccharide transport protein MST1 & $1 \mathrm{E}-114$ & 0.00090 & 0.082 & 2.72 \\
\hline Ta.3922.2.S1_at & Nitrilase 2 & $6 \mathrm{E}-44$ & 0.00004 & 0.047 & 2.45 \\
\hline Ta.11022.1.S1__a_at & $O$-methyltransferase ZRP4 & $2 \mathrm{E}-54$ & 0.00079 & 0.078 & -2.10 \\
\hline Ta.5210.1.S1_at & Peptide transporter protein & $8 \mathrm{E}-68$ & 0.00018 & 0.048 & 2.49 \\
\hline TaAffx.33594.1.A1_x_at & Plasma membrane protein 3 & $2 \mathrm{E}-13$ & 0.00084 & 0.080 & 2.32 \\
\hline Ta.5521.1.A1_at & Pyrophosphate:fructose-6-phosphate 1-phosphotransferase & $6 \mathrm{E}-76$ & 0.00021 & 0.113 & 2.12 \\
\hline Ta.13281.1.S1_at & Pyruvate decarboxylase & 0 & 0.00045 & 0.066 & 3.78 \\
\hline Ta.1404.1.S1_at & Ribulose bisphosphate carboxylase activase B & 0 & 0.00033 & 0.058 & 2.90 \\
\hline Ta.10480.1.S1_a_at & S-like Rnase & $1 \mathrm{E}-148$ & 0.00075 & 0.077 & -2.96 \\
\hline Ta.11773.1.S1_at & Sphingosine-1-phosphate lyase & $2 \mathrm{E}-86$ & 0.00072 & 0.077 & 2.28 \\
\hline Ta.22683.1.S1_at & Thiolase & $1 \mathrm{E}-100$ & 0.00003 & 0.047 & 2.13 \\
\hline Ta.4921.1.S1_at & UDP-galactose transporter & $1 \mathrm{E}-146$ & 0.00015 & 0.048 & 3.82 \\
\hline Ta.10308.3.S1̄_x_at & UDP-galactose/UDP-glucose transporter & $1 \mathrm{E}-24$ & 0.00056 & 0.149 & 2.07 \\
\hline TaAffx.64672.1.S1_at & UDP-glucose:salicylic acid glucosyltransferase & $1 \mathrm{E}-92$ & 0.00027 & 0.120 & 3.26 \\
\hline Ta.23342.1.S1_at & UMP synthase 1 & $4 \mathrm{E}-93$ & 0.00045 & 0.066 & 5.00 \\
\hline Ta.23309.1.S1_at & UMP synthase 1 & $8 \mathrm{E}-44$ & 0.00028 & 0.055 & 6.07 \\
\hline \multicolumn{6}{|l|}{ Defense and stress } \\
\hline TaAffx.108909.1.S1_at & 4-Aminobutyrate aminotransferase & $5 \mathrm{E}-37$ & 0.00001 & 0.038 & 7.40 \\
\hline Ta.21353.1.S1_at & Acetone-cyanohydrin lyase & $2 \mathrm{E}-72$ & 0.00052 & 0.067 & 5.48 \\
\hline TaAffx.108908.1.S1_x_at & Antifungal zeamatin-like protein & 2E-92 & 0.00070 & 0.076 & 17.49 \\
\hline Ta.336.2.S1_at & Caffeic acid $O$-methyltransferase & 0 & 0.00098 & 0.082 & 2.30 \\
\hline TaAffx.108314.1.S1_at & Caffeic acid $O$-methyltransferase & $1 \mathrm{E}-78$ & 0.00015 & 0.048 & 12.37 \\
\hline Ta.14903.1.S1_at & Chalcone synthase & $3 \mathrm{E}-89$ & 0.00055 & 0.069 & 33.79 \\
\hline TaAffx.108353.1.S1_at & Chalcone synthase & $8 \mathrm{E}-44$ & 0.00011 & 0.048 & 63.66 \\
\hline Ta.2784.1.A1_at & Chitinase 1 & $1 \mathrm{E}-149$ & 0.00095 & 0.082 & 8.50 \\
\hline Ta.2278.3.S1_x_at & Chitinase 2 & $1 \mathrm{E}-61$ & 0.00085 & 0.080 & 15.13 \\
\hline Ta.23317.3.S1_a_at & Copine I & $1 \mathrm{E}-114$ & 0.00036 & 0.060 & 2.24 \\
\hline TaAffx.53952.1.S1_at & Cytochrome P450 & $6 \mathrm{E}-34$ & 0.00053 & 0.068 & 7.61 \\
\hline TaAffx.107979.1.S1_at & Cytochrome P450 & $2 \mathrm{E}-37$ & 0.00019 & 0.049 & 3.49 \\
\hline TaAffx.55601.1.S1_at & Cytochrome P450 & $3 \mathrm{E}-23$ & 0.00015 & 0.048 & 14.18 \\
\hline Ta.3976.1.S1_at - & Flavanone 3-hydroxylase & $8 \mathrm{E}-142$ & 0.00014 & 0.048 & 4.42 \\
\hline Ta.20804.1.S1_at & Germin-like protein 1 & $4 \mathrm{E}-20$ & 0.00024 & 0.051 & -4.90 \\
\hline Ta.25377.1.S1_at & Glutathione S-transferase, & $3 \mathrm{E}-60$ & 0.00020 & 0.049 & 3.22 \\
\hline Ta.8128.2.S1_āat & Heat shock protein 70, DnaJ-type & $3 \mathrm{E}-27$ & 0.00017 & 0.048 & 2.46 \\
\hline TaAffx.107458.1.S1_s_at & Heat shock protein 70 , DnaK-type & $1 \mathrm{E}-128$ & 0.00069 & 0.076 & 2.39 \\
\hline Ta.21335.1.S1_at & Heat shock protein 70, DnaK-type & $1 \mathrm{E}-128$ & 0.00024 & 0.051 & 2.74 \\
\hline Ta.22674.1.A1_a_at & Iron/ascorbate-dependent oxidoreductase & $4 \mathrm{E}-72$ & 0.00062 & 0.072 & 3.36 \\
\hline Ta.9742.1.S1_at & Lipoxygenase & $1 \mathrm{E}-123$ & 0.00029 & 0.056 & 2.06 \\
\hline Ta.4873.1.S1_at & Omega- 3 fatty acid desaturase, plastid & 0 & 0.00035 & 0.059 & -2.21 \\
\hline \multirow[t]{2}{*}{ TaAffx.83275.1.S1_at } & Pathogenesis-related protein $1 \mathrm{a}$ & $4 \mathrm{E}-27$ & 0.00054 & 0.069 & 42.53 \\
\hline & & & & \multicolumn{2}{|c|}{ (continued on next page) } \\
\hline
\end{tabular}

\footnotetext{
${ }^{a}$ Predicted function based on the best BlastX hit (E-value threshold $\left.\bullet 10-10\right)$ provided by HarvEST.

${ }^{\mathrm{b}} P$ value threshold $\leq 0.001$.

${ }^{c} q$ Values are derived from the method described by Storey and Tibshirani (2003).

${ }^{\mathrm{d}}$ Based on fold-regulation cut-off of $\geq 2.0$.

${ }^{\mathrm{e}}$ Cellular metabolism, structure, and maintenance.
} 
Table 1. (continued from preceding page)

\begin{tabular}{|c|c|c|c|c|c|}
\hline Probe set ID & Predicted function $^{\mathrm{a}}$ & E value & $P$ value ${ }^{b}$ & $q$ value $^{\mathrm{c}}$ & Fold change $^{d}$ \\
\hline TaAffx.108556.1.S1_x_at & Pathogenesis-related protein 4 & $2 \mathrm{E}-75$ & 0.00030 & 0.056 & 7.73 \\
\hline TaAffx.116570.1.S1_at & Pathogenesis-related protein 4 & $5 \mathrm{E}-69$ & 0.00005 & 0.047 & 17.55 \\
\hline Ta.24106.1.S1_x_at & Peroxidase & $6 \mathrm{E}-73$ & 0.00016 & 0.048 & 5.31 \\
\hline Ta.22564.2.S1_a_at & Peroxidase & $1 \mathrm{E}-107$ & 0.00072 & 0.077 & 6.03 \\
\hline Ta.82.1.S1_at & Peroxidase & $1 \mathrm{E}-174$ & 0.00024 & 0.051 & 6.87 \\
\hline Ta.24715.1.S1_at & Peroxidase & $1 \mathrm{E}-151$ & 0.00004 & 0.047 & 8.37 \\
\hline Ta.962.1.A1_at & Peroxidase 15 , class III & $4 \mathrm{E}-75$ & 0.00035 & 0.060 & 5.15 \\
\hline Ta.8893.1.S1_at & Seven transmembrane MLO family protein & 4E-94 & 0.00033 & 0.058 & 2.03 \\
\hline Ta.25053.1.S1_at & Thaumatin-like protein & $1 \mathrm{E}-135$ & 0.00023 & 0.051 & 4.67 \\
\hline Ta.13.1.S1_at & WIR1 & $2 \mathrm{E}-40$ & 0.00075 & 0.077 & 4.50 \\
\hline Ta.97.1.S1_at & WIR1 & $2 \mathrm{E}-43$ & 0.00015 & 0.048 & 9.64 \\
\hline Ta.3133.1.S1_x_at & WIR1A & $4 \mathrm{E}-24$ & 0.00017 & 0.048 & 6.09 \\
\hline Ta.97.2.S1_x_at & WIR1A & $9 \mathrm{E}-45$ & 0.00013 & 0.048 & 12.95 \\
\hline Ta.25081.1.A1_at & Wound-induced protein 1 & $1 \mathrm{E}-21$ & 0.00081 & 0.078 & 3.76 \\
\hline Ta.26048.1.S1_x_at & $\beta$-1,3-Glucanase & 2E-94 & 0.00044 & 0.066 & 4.26 \\
\hline TaAffx.110196.1.S1_s_at & $\beta$-1,3-Glucanase & $3 \mathrm{E}-65$ & 0.00018 & 0.048 & 5.69 \\
\hline Ta.223.1.S1_at & $\beta$-1,3-Glucanase & 0 & 0.00037 & 0.060 & 6.49 \\
\hline Ta.20121.1.S1_x_at & $\beta-1,3-$ Glucanase & $4 \mathrm{E}-45$ & 0.00008 & 0.048 & 10.35 \\
\hline Ta.8584.1.S1_at & $\beta-1,3$-Glucanase & $3 \mathrm{E}-87$ & 0.00018 & 0.048 & 11.69 \\
\hline TaAffx.107478.1.S1_at & $\beta$-1,3-Glucanase & $5 \mathrm{E}-52$ & 0.00001 & 0.038 & 16.21 \\
\hline TaAffx.24475.1.S1_x_at & $\beta$-1,3-Glucanase & $2 \mathrm{E}-17$ & 0.00001 & 0.038 & 19.69 \\
\hline Ta.21120.1.S1_at & $\beta$-1,3-Glucanase & $2 \mathrm{E}-41$ & 0.00016 & 0.048 & 6.66 \\
\hline TaAffx.131249.1.S1_at & $\beta$-1,3-Glucanase & $8 \mathrm{E}-47$ & 0.00010 & 0.106 & 12.29 \\
\hline \multicolumn{6}{|l|}{ Signal transduction } \\
\hline Ta.5041.1.S1_at & CBL-interacting protein kinase 23 & $1 \mathrm{E}-122$ & 0.00046 & 0.066 & 3.96 \\
\hline TaAffx.70995.1.S1_at & Mitogen-activated protein kinase kinase & $2 \mathrm{E}-28$ & 0.00051 & 0.067 & 2.16 \\
\hline TaAffx.55699.1.S1_at & Protein kinase & 7E-17 & 0.00003 & 0.095 & 2.64 \\
\hline TaAffx.25815.1.S1_at & Protein kinase & $5 \mathrm{E}-42$ & 0.00091 & 0.082 & 2.87 \\
\hline Ta.27455.1.S1_at & Protein kinase & $1 \mathrm{E}-108$ & 0.00012 & 0.048 & 3.96 \\
\hline TaAffx.23192.2.S1_at & Rust resistance kinase Lr10 & $6 \mathrm{E}-45$ & 0.00012 & 0.048 & 2.49 \\
\hline TaAffx.5899.1.S1_at & Serine-threonine kinase receptor & $4 \mathrm{E}-21$ & 0.00081 & 0.078 & 2.68 \\
\hline TaAffx.78449.1.S1_at & Serine-threonine kinase, wall-associated & $2 \mathrm{E}-54$ & 0.00015 & 0.048 & 2.75 \\
\hline TaAffx.110649.1.S1_at & Serine-threonine kinase, wall-associated & $4 \mathrm{E}-13$ & 0.00096 & 0.082 & 3.78 \\
\hline Ta.10555.1.A1_at & Serine-threonine protein kinase & $1 \mathrm{E}-26$ & 0.00029 & 0.056 & 2.61 \\
\hline Ta.4762.1.S1_at & Serine-threonine protein kinase SAPK7 & 1E-136 & 0.00046 & 0.066 & 2.14 \\
\hline Ta.26901.1.S1_at & Serine-threonine protein kinase & $1 \mathrm{E}-100$ & 0.00052 & 0.068 & 2.46 \\
\hline TaAffx.129414.2.S1_x_at & TAK33 & $4 \mathrm{E}-53$ & 0.00006 & 0.048 & 2.44 \\
\hline TaAffx.55952.1.S1_at & TAK33 & $4 \mathrm{E}-28$ & 0.00028 & 0.055 & 3.02 \\
\hline \multicolumn{6}{|l|}{ Transcription } \\
\hline Ta.27316.1.S1_at & AP2 domain protein & $1 \mathrm{E}-147$ & 0.00008 & 0.048 & 2.68 \\
\hline Ta.14467.2.S1_at & bZIP transcription factor-like & 2E-11 & 0.00081 & 0.078 & 2.12 \\
\hline TaAffx.24604.1.S1_at & DNA-binding protein RAV2-like & $2 \mathrm{E}-10$ & 0.00084 & 0.170 & 3.64 \\
\hline Ta.16907.1.S1_at & WRKY transcription factor 45 & $3 \mathrm{E}-80$ & 0.00074 & 0.077 & 4.02 \\
\hline Ta.8614.1.S1_at & WRKY transcription factor 45 & $8 \mathrm{E}-57$ & 0.00009 & 0.106 & 4.34 \\
\hline \multicolumn{6}{|l|}{ Transport } \\
\hline Ta.9295.1.A1_at & Multidrug resistance-like $\mathrm{ABC}$ transporter & $1 \mathrm{E}-100$ & 0.00007 & 0.048 & 2.23 \\
\hline Ta.9831.1.S1_s_at & MRP-like ABC transporter & $5 \mathrm{E}-82$ & 0.00069 & 0.076 & 2.26 \\
\hline \multicolumn{6}{|l|}{ Unclassified } \\
\hline Ta.25531.2.A1_at & 33-kDa secretory protein expressed & $4 \mathrm{E}-45$ & 0.00011 & 0.048 & 3.50 \\
\hline Ta.25531.1.A1_at & $33-\mathrm{kDa}$ secretory protein expressed & $2 \mathrm{E}-24$ & 0.00040 & 0.064 & 4.17 \\
\hline TaAffx.15065.1.S1_at & B12D protein & $1 \mathrm{E}-36$ & 0.00004 & 0.095 & 2.11 \\
\hline TaAffx.17098.1.S1_at & Coiled-coil-helix domain containing protein & $1 \mathrm{E}-18$ & 0.00021 & 0.051 & 2.11 \\
\hline TaAffx.110675.1.S1_at & HGA1 & $7 \mathrm{E}-77$ & 0.00095 & 0.082 & 5.22 \\
\hline Ta.4117.3.S1_at & HGA6 & $1 \mathrm{E}-41$ & 0.00098 & 0.178 & 3.81 \\
\hline Ta.28010.1.S1_s_at & Hypothetical protein & $2 \mathrm{E}-25$ & 0.00091 & 0.082 & 2.32 \\
\hline TaAffx.130713.1.A1_at & Hypothetical protein & $6 \mathrm{E}-20$ & 0.00013 & 0.048 & 2.67 \\
\hline Ta.14221.1.S1_s_at & Hypothetical protein & $3 \mathrm{E}-11$ & 0.00038 & 0.062 & 2.95 \\
\hline Ta.9905.1.S1_at & Hypothetical protein & $1 \mathrm{E}-10$ & 0.00049 & 0.066 & 2.98 \\
\hline TaAffx.80336.2.S1_x_at & Hypothetical protein & $2 \mathrm{E}-41$ & 0.00022 & 0.051 & 3.55 \\
\hline TaAffx.110222.1.S1_x_at & Leucine-rich repeat-containing extracellular glycoprotein & $2 \mathrm{E}-40$ & 0.00053 & 0.068 & 4.45 \\
\hline Ta.22662.1.S1_at & ORFX & $9 \mathrm{E}-45$ & 0.00078 & 0.077 & 2.93 \\
\hline TaAffx.16487.1.A1_at & Selenium binding protein & $2 \mathrm{E}-49$ & 0.00076 & 0.077 & 2.02 \\
\hline TaAffx.86898.1.S1_at & Selenium binding protein & $1 \mathrm{E}-16$ & 0.00085 & 0.080 & 2.38 \\
\hline Ta.5107.1.A1_at & $\mathrm{X} 1$ & $1 \mathrm{E}-85$ & 0.00044 & 0.066 & 3.53 \\
\hline \multicolumn{6}{|l|}{ No annotation available } \\
\hline TaAffx.52233.1.S1_at & $\ldots$ & $\ldots$ & 0.00014 & 0.048 & 2.05 \\
\hline Ta.5562.1.A1_at & $\ldots$ & $\ldots$ & 0.00097 & 0.082 & 2.08 \\
\hline Ta.20974.1.S1_x_at & $\ldots$ & $\ldots$ & 0.00072 & 0.077 & 2.16 \\
\hline Ta.11185.2.A1_at & $\ldots$ & $\ldots$ & 0.00047 & 0.066 & 2.17 \\
\hline Ta.8773.2.S1_x_at & $\ldots$ & $\ldots$ & 0.00062 & 0.072 & 2.26 \\
\hline \multirow[t]{2}{*}{ Ta.23115.2.S1_x_at } & $\ldots$ & $\ldots$ & 0.00045 & 0.066 & 2.31 \\
\hline & & & & \multicolumn{2}{|c|}{ (continued on next page) } \\
\hline
\end{tabular}


Table 1. (continued from preceding page)

\begin{tabular}{|c|c|c|c|c|c|}
\hline Probe set ID & Predicted function $^{a}$ & E value & $P$ value $^{b}$ & $q$ value $^{c}$ & Fold change $^{d}$ \\
\hline Ta.12731.1.A1_s_at & $\ldots$ & $\ldots$ & 0.00034 & 0.059 & 2.35 \\
\hline TaAffx.37298.1.A11_at & $\ldots$ & $\ldots$ & 0.00069 & 0.076 & 2.48 \\
\hline Ta.16190.1.A1_x_at & $\ldots$ & $\ldots$ & 0.00062 & 0.072 & 2.52 \\
\hline TaAffx.15430.1.A1_at & $\ldots$ & $\ldots$ & 0.00021 & 0.051 & 2.89 \\
\hline Ta.22628.1.S1_at & $\ldots$ & $\ldots$ & 0.00004 & 0.047 & 3.23 \\
\hline Ta.11185.1.A1_at & $\ldots$ & $\ldots$ & 0.00026 & 0.055 & 3.43 \\
\hline TaAffx.59573.1.S1_at & $\ldots$ & $\ldots$ & 0.00076 & 0.077 & 3.44 \\
\hline Ta.28646.1.S1_s_at & $\ldots$ & $\ldots$ & 0.00059 & 0.071 & 3.56 \\
\hline Ta.20197.1.S1_at & $\ldots$ & $\ldots$ & 0.00004 & 0.047 & 3.61 \\
\hline Ta.8907.1.S1_at & $\ldots$ & $\ldots$ & 0.00032 & 0.123 & 4.30 \\
\hline TaAffx.109252.1.S1_at & $\ldots$ & $\ldots$ & 0.00011 & 0.048 & 4.44 \\
\hline TaAffx.104820.1.S1_at & $\ldots$ & $\ldots$ & 0.00003 & 0.047 & 4.50 \\
\hline TaAffx.82859.1.S1_at & $\ldots$ & $\ldots$ & 0.00023 & 0.051 & 6.72 \\
\hline Ta.23307.1.S1_at & $\ldots$ & $\ldots$ & 0.00064 & 0.073 & 7.72 \\
\hline TaAffx.81266.1.S1_at & $\ldots$ & $\ldots$ & 0.00022 & 0.114 & 8.52 \\
\hline Ta.18678.1.S1_at & $\ldots$ & $\ldots$ & 0.00009 & 0.048 & 9.27 \\
\hline Ta.14836.1.A1_at & $\ldots$ & $\ldots$ & 0.00046 & 0.144 & 12.47 \\
\hline TaAffx.82716.1.S1_at & $\ldots$ & $\ldots$ & 0.00009 & 0.048 & 14.23 \\
\hline Ta.27760.1.S1_at & $\ldots$ & $\ldots$ & 0.00041 & 0.138 & 25.48 \\
\hline TaAffx.46097.2.S1_at & $\ldots$ & $\ldots$ & 0.00024 & 0.114 & 26.41 \\
\hline
\end{tabular}

Table 2. Numbers of differentially expressed genes identified in Thatcher (Tc) wheat and Thatcher $L r$ near-isogenic lines inoculated with Puccinia triticina versus mock inoculations

\begin{tabular}{|c|c|c|c|c|c|c|c|c|}
\hline \multirow[b]{3}{*}{ Genotype } & \multicolumn{8}{|c|}{ Days postinoculation } \\
\hline & \multicolumn{2}{|c|}{ Upregulated } & \multicolumn{2}{|c|}{ Downregulated } & \multicolumn{2}{|c|}{ Present } & \multicolumn{2}{|c|}{ Absent } \\
\hline & 3 & 7 & 3 & 7 & 3 & 7 & 3 & 7 \\
\hline $\mathrm{Tc}$ & 0 & 97 & 0 & 54 & 0 & 14 & 0 & 1 \\
\hline $\mathrm{Tc} L r 1$ & 0 & 0 & 0 & 0 & 0 & 0 & 0 & 0 \\
\hline TcLr34 & 129 & 123 & 5 & 2 & 17 & 7 & 0 & 0 \\
\hline
\end{tabular}

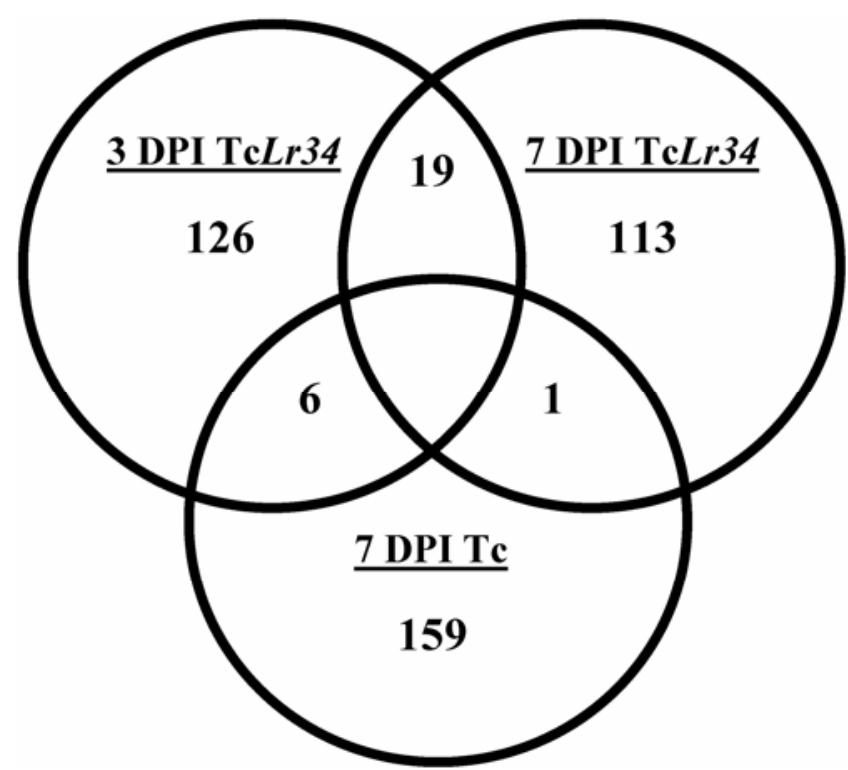

Fig. 2. Overlap of probe sets detecting differentially expressed genes $(P$ value $\leq 0.001$, fold change $\geq 2.0$ ) after inoculation with Puccinia triticina race 1 in the susceptible wheat $\mathrm{cv}$. Thatcher $(\mathrm{Tc})$ at 7 days postinoculation (dpi), and in the Tc near-isoline with $\operatorname{Lr} 34$ (TcLr34) at both 3 and 7 dpi.

pyruvate, the latter of which is the primary substrate for the TCA cycle.

Few genes typically considered to play a role in defense and stress were differentially expressed in $7 \mathrm{dpi}$ Tc. Among those that were detected were genes encoding stress-related proteins such as a cold-acclimation protein; an early-drought-induced protein; a sugar-starvation-induced protein; a low-temperature and salt-responsive protein; and WSI76, which is responsive to

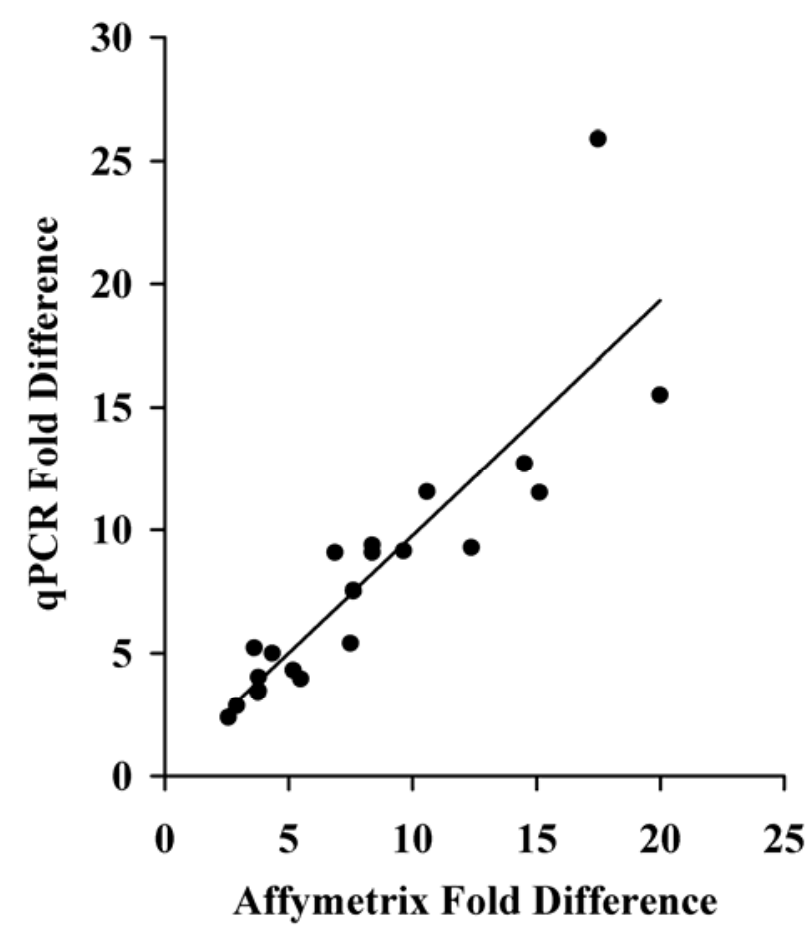

Fig. 3. Comparison of quantitative gene expression differences in Puccinia triticina-infected and mock-inoculated Thatcher (Tc) wheat and $L r$ near-isolines using Affymetrix GeneChip Wheat Genome Arrays and quantitative real-time reverse-transcription polymerase chain reaction (qPCR). Genes selected for qPCR exhibited both a wide range of $P$ value and fold-regulation differences in the microarray analysis and also have diverse functions in the plant. Quantification of gene expression was performed using the comparative cycle threshold $\left(\mathrm{C}_{\mathrm{T}}\right)$ method $\left(\Delta \Delta \mathrm{C}_{\mathrm{T}}\right)$. For purposes of figure display, gene expression quantification data for chalcone synthase is not included, but results were highly concordant (microarray expression difference $=63.66$, qPCR expression difference $=62.81)$.

water stress. Other differentially expressed defense-related genes include those encoding $\beta$-1,3-glucanase, thaumatin-like protein, and flavanone 3-hydroxylase. Several genes encoding kinases were also differentially expressed, including calciumand calmodulin-dependent kinases and serine/threonine kinases. Genes involved in transcriptional regulation encoded various classes of transcription factors such as basic helix-loop-helix, MADS box, Myb, and WRKY, with both up- and downregu- 
Table 3. Upregulated wheat genes encoding enzymes of energy-producing pathways in Puccinia triticina-inoculated versus mock-inoculated TcLr34 3 days after inoculation

\begin{tabular}{|c|c|c|c|c|c|}
\hline Probe set ID & Predicted function & Abbreviation & $P$ value ${ }^{a}$ & $q$ value $^{\mathrm{b}}$ & Fold change $^{c}$ \\
\hline \multicolumn{6}{|l|}{ Glycolysis } \\
\hline TaAffx.8265.1.S1_at & 6-Phosphofructokinase & PFK & 0.00017 & 0.04823 & 2.126 \\
\hline Ta.5521.1.A1_at & Pyrophosphate:fructose-6-phosphate 1-phosphotransferase & PPi-PFK & 0.00021 & 0.113 & 2.122 \\
\hline \multicolumn{6}{|l|}{ Pyruvate metabolism } \\
\hline Ta.29951.1.S1_at & Pyruvate dehydrogenase & $\mathrm{PDH}$ & 0.00118 & 0.08462 & 2.435 \\
\hline Ta.26921.3.S1_x_at & Lactate dehydrogenase & $\mathrm{LDH}$ & $1.1 \mathrm{E}-05$ & 0.03809 & 1.71 \\
\hline \multicolumn{6}{|l|}{ PDH-bypass } \\
\hline Ta.13281.1.S1_at & Pyruvate decarboxylase & PDC & 0.00045 & 0.06554 & 3.784 \\
\hline Ta.2107.1.S1_s_at & Aldehyde dehydrogenase & ALDH & 0.00068 & 0.07571 & 3.343 \\
\hline \multicolumn{6}{|l|}{ CoA biosynthesis } \\
\hline Ta.16065.1.A1_at & Pantothenate kinase & CoA-A & 0.00427 & 0.1223 & 1.759 \\
\hline TaAffx.63502.1.S1_at & 4'-Phosphopantetheine adenylyltransferase & CoA-D & 0.00012 & 0.04823 & 2.428 \\
\hline \multicolumn{6}{|l|}{$\beta$-oxidation } \\
\hline Ta.25699.1.S1_at & Acyl-CoA dehydrogenase & $\mathrm{AD}$ & 0.00304 & 0.1105 & 1.803 \\
\hline TaAffx.49165.2.S1_at & Enoyl-CoA hydratase & $\mathrm{EH}$ & 0.00493 & 0.1296 & 1.588 \\
\hline Ta.5518.1.S1_at & Acetyl-CoA C-acyltransferase & ACAT & 0.00185 & 0.09296 & 5.345 \\
\hline \multicolumn{6}{|l|}{ TCA cycle ${ }^{\mathrm{d}}$} \\
\hline Ta.970.2.S1_a_at & Citrate synthase & $\mathrm{CS}$ & 0.00013 & 0.04823 & 2.303 \\
\hline Ta.968.1.S1_at & $\alpha$-Ketoglutarate dehydrogenase & $\alpha-\mathrm{KGDH}$ & 0.00035 & 0.1256 & 2.572 \\
\hline \multicolumn{6}{|l|}{ GABA shunt } \\
\hline Ta.1870.1.S1_a_at & Glutamate dehydrogenase & GDH & 0.00175 & 0.09296 & 3.566 \\
\hline Ta.7341.1.S1_at & Glutamate decarboxylase & GDC & $4 \mathrm{E}-05$ & 0.04665 & 1.846 \\
\hline TaAffx.108909.1.S1_at & 4-Aminobutyrate aminotransferase & GAT & $1.4 \mathrm{E}-05$ & 0.03809 & 7.399 \\
\hline
\end{tabular}

a Based on $P$ value cut-off $\leq 0.005$.

${ }^{\mathrm{b}} q$ Values are derived from the method described by Storey and Tibshirani (2003).

${ }^{c}$ Based on fold-regulation cut-off of $\geq 1.5$.

${ }^{\mathrm{d}} \mathrm{TCA}=$ tricarboxylic acid.

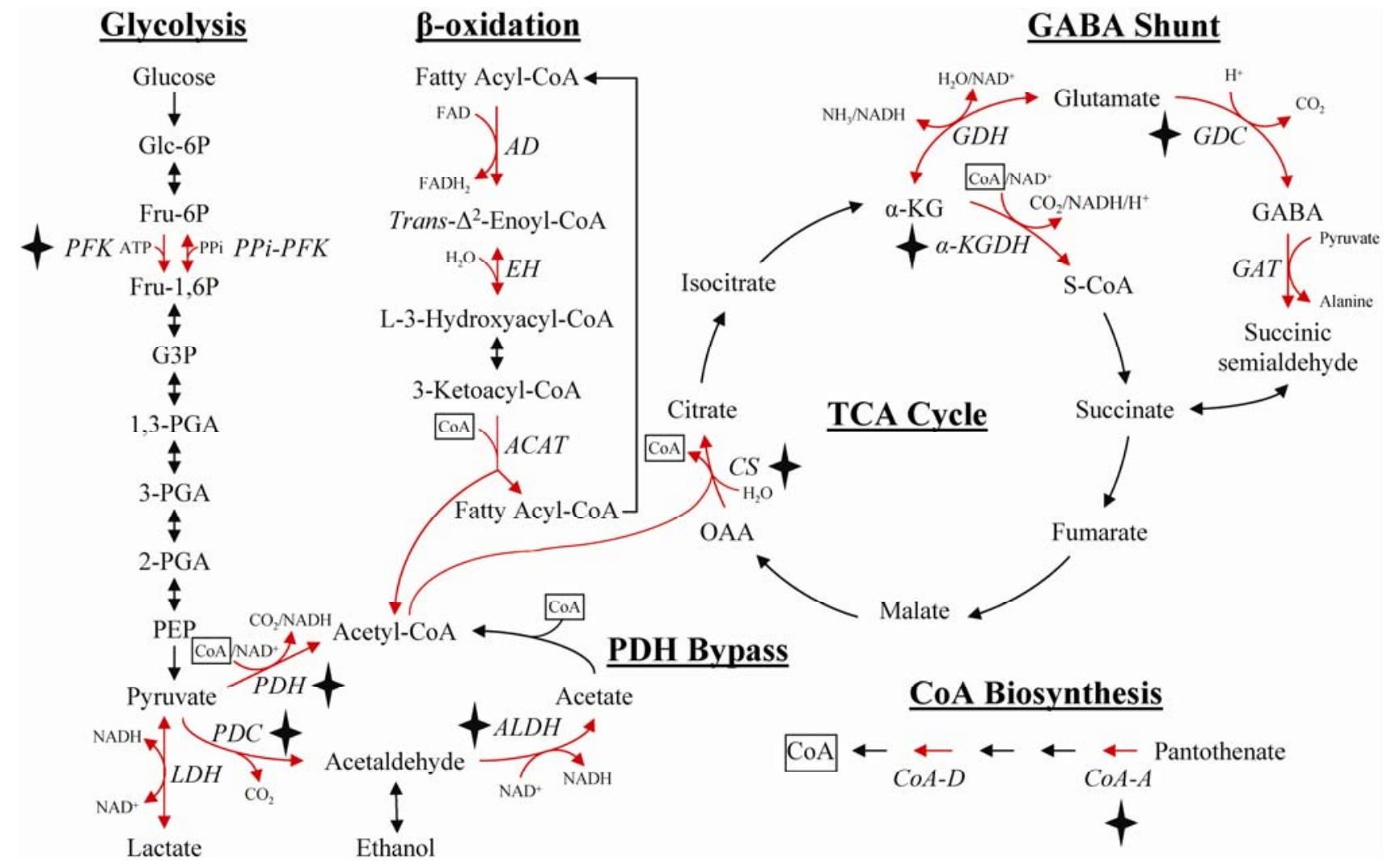

Fig. 4. Genes of glycolysis, pyruvate metabolism including the PDH-bypass, $\beta$-oxidation, CoA biosynthesis, the GABA shunt, and the tricarboxylic acid (TCA) cycle that were upregulated in P. triticina-inoculated versus mock-inoculated TcLr34 at 3 days postinoculation. Red arrows highlight metabolic steps for which the relevant coding genes are upregulated in TcLr34 in response to P. triticina. Stars indicate enzymatic steps that are considered rate-limiting in their respective pathway.

lation detected depending on the specific gene. A set of genes encoding proteins involved with transport such as major facilitator superfamily antiporters and several carbohydrate and amino acid transporters were also differentially expressed.
Pathogen-responsive genes in TcLr1. As noted previously, no genes were identified in TcLrl that met our statistical or fold-change thresholds for differential expression at either 3 or 7 dpi. 
Pathogen-responsive genes in TcLr34. At 3 dpi in TcLr34, 146 genes were significantly upregulated and only 5 genes were downregulated in P. triticina-infected plants. Many of the upregulated genes identified in pathogen-treated TcLr34 are involved with defense and stress responses. These include genes encoding various pathogenesis-related $(\mathrm{PR})$ proteins $(\beta$ 1,3-glucanase, chitinases, PR-1, and PR-4), peroxidase, antifungal zeamatin-like protein, cytochrome P450, and WIR1, which are all associated with pathogen defense (Table 1). Several other genes previously reported to be induced upon infection or wounding in other pathosystems were also induced in TcLr34, including those encoding lipoxygenase, acetone-cyanohydrin lyase, copine, and both thaumatin-like and woundinduced proteins (Table 1).

A gene for glutathione $S$-transferase, which has antioxidant properties, was upregulated in response to $P$. triticina, as were three genes encoding heat shock proteins, often induced in stress conditions. Several phenylpropanoid pathway genes were upregulated at the 3 dpi timepoint, including those for caffeic acid $O$-methyltransferase involved in lignin biosynthesis, and both chalcone synthase and flavanone 3-hydroxylase that participate in flavonoid biosynthesis (Table 1). Interestingly, defense-related genes germin-like 1 (oxalate oxidase) and omega-3 fatty acid desaturase were downregulated in TcLr34 at 3 dpi (Table 1), contrary to other studies (Hurkman and Tanaka 1996; Martín et al. 1999).

A set of genes involved in cell signaling and transcriptional activation, such as those encoding bZIP, AP2, and WRKY transcription factors and several classes of serine/threonine and MAP kinases were also induced in TcLr34 at 3 dpi. Certain genes involved in transport functions, such as ABC transporters, were also upregulated (Table 1).

Finally, a significant portion of genes differentially expressed in P. triticina-infected TcLr34 at 3 dpi encoded proteins that function in primary energy metabolism pathways. These include enzymes located at different points in the interrelated metabolic pathways glycolysis, the TCA cycle, the pyruvate dehydrogenase bypass, $\beta$-oxidation, the GABA shunt, and CoA biosynthesis. In light of these results, we undertook a manual pathway analysis by requerying our data set at a moderately lower stringency ( $P$ value $\leq 0.005$, fold-regulation $\geq 1.5$ ) specifically to determine whether upregulation of other genes in these pathways or others associated with them could be detected (van Baarlen et al. 2007). This targeted metabolic pathway-based analysis identified differences in expression for several additional genes in these and additional interrelated pathways (Table 3; Fig. 4).

At 7 dpi in TcLr34, 130 genes were upregulated and 2 genes were downregulated in pathogen-inoculated plants. This gene set showed little overlap with differentially expressed genes identified at 3 dpi in TcLr34 or with differentially expressed genes identified at $7 \mathrm{dpi}$ in Tc (Fig. 2). At $7 \mathrm{dpi}$, inoculation with $P$. triticina led to increased transcript levels of genes generally associated with the response to abiotic stresses in TcLr34. For example, a gene for 2-alkenal reductase was induced at $7 \mathrm{dpi}$; this gene has high sequence similarity to Arabidopsis thaliana gene At5g16970 that plays a role in plant antioxidant defense and possibly $\mathrm{NAD}(\mathrm{P}) / \mathrm{NAD}(\mathrm{P}) \mathrm{H}$ homeostasis (Mano et al. 2005; Noctor et al. 2006). Several genes that may have antioxidant properties were upregulated, including cytochrome P-450, peroxidase, and glutathione $S$-transferase genes. Several PR proteins were also upregulated, including $\beta$ 1,3-glucanase, chitinase classes 1-3, PR-1, and PR-4. Multiple phenylpropanoid metabolism-related genes were upregulated, including those for caffeic acid $O$-methyltransferase, cinnamylalcohol dehydrogenase, anthocyanidin synthase, chalcone synthase, flavonoid 7-O-methyltransferase, and agmatine couma- royltransferase. Other genes upregulated and involved with plant defense encode antifungal zeamatin-like protein and WIR1.

Genes encoding enzymes involved in cell metabolism that were upregulated had diverse functions. A gene encoding cycloartenol synthase, a precursor for sterol production, was the most highly upregulated (6.1-fold) gene in pathogen-inoculated versus mock-inoculated TcLr34 plants at 7 dpi. The only instance where transcript for a cell-metabolism-associated gene was less abundant in the pathogen-inoculated plants (fold difference of 2.0) was for carbonic anhydrase, an enzyme that catalyzes the reversible conversion of $\mathrm{CO}_{2}$ to $\mathrm{HCO}_{3}$ involved in carbon assimilation and associated with photosynthesis ( $\mathrm{Li}$ et al. 2004). Several genes encoding proteins involved in signal transduction (MAPKKK, serine/threonine protein kinase) and transcription (Myb2, WRKY) were upregulated, as were some genes involved in transport functions such as ABC, MATE efflux, and pleiotropic drug transporters.

\section{DISCUSSION}

Many studies have focused on wheat defense responses to a variety of pathogens (e.g., Hill-Ambroz et al. 2006; Kang and Buchenauer 2000; Kong et al. 2005; Pritsch et al. 2001), including P. triticina (Danna et al. 2002; Rampitsch et al. 2006; Thara et al. 2003; Zhang et al. 2003). In general, these studies have detected the upregulation of defense-related genes in both susceptible and resistant genotypes, with a tendency toward greater and more rapid expression of these genes in incompatible (resistant) interactions. However, these studies looked at small numbers of genes and none examined race-nonspecific leaf rust resistance. A recent study by Hulbert and associates (2007) did analyze transcriptional changes associated with Lr34-mediated resistance in Jupateco and Thatcher wheat backgrounds at a single timepoint (62 h postinoculation). Using a $P$ value threshold of $\leq 0.05$ coupled to a fold-change threshold of 5.0, their analysis identified 59 genes upregulated in response to $P$. triticina inoculation, including typical PR proteins, cytochrome P450s, and genes involved in phenylpropanoid metabolism (Hulbert et al. 2007). For their study, necrotic and chlorotic portions of leaf tips were removed and the remaining leaf was sectioned and used for gene expression comparisons between apical and basal halves of the leaf (Hulbert et al. 2007). Therefore, it is difficult to compare their results with ours in detail. However, it is worth noting that only 21 probe sets detecting differential expression in response to $P$. triticina were found in common between the studies. To our knowledge, our study is the first to compare transcriptional changes associated with HR and race-nonspecific leaf rust resistance in wheat across different timepoints.

In our study, we compared changes that occur in the wheat transcriptome in a compatible leaf rust interaction, an $R$-genemediated incompatible interaction conferred by $L r l$, and racenonspecific resistance mediated by Lr34. In the compatible interaction, we found no differentially expressed genes at $3 \mathrm{dpi}$ but over 160 at $7 \mathrm{dpi}$. This is in general concurrence with other studies showing that response to pathogens in the compatible interaction lags behind the incompatible interaction, likely because plant cells do not recognize the pathogen until the disease has progressed considerably, or due to pathogen suppression of plant defense mechanisms (Jones and Dangl 2006).

Somewhat surprisingly, using our statistical and fold-change thresholds, we did not identify any differentially expressed genes in the $R$-gene-mediated response associated with $L r l$ at either 3 or $7 \mathrm{dpi}$. There are several possible explanations for this result. The HR is a highly efficient process confined to few cells in proximity to points of infection. Genes that were 
differentially expressed in response to the pathogen might simply have not been detectable due to mass RNA dilution from the majority of cells not undergoing the HR. Indeed, a recent study has recognized this issue and sought to circumvent it by microextracting cell-specific mRNA from infected or resistant cells for transcript analysis (Gjetting et al. 2007). Alternatively, the absence of differentially expressed transcripts associated with $L r l$ resistance may reflect a very rapid HR after inoculation leading to an abrupt halt to the $P$. triticina infection process, followed by a return to basal levels of gene expression by 3 dpi.

Our results clearly indicate that $L r 34$ conditions an active defense response as indicated by the upregulation of many genes involved in defense and stress early in the resistance reaction (Table 1). Although Lr34 does not condition a HR, the resistance response of $\operatorname{Lr} 34$ at 3 dpi shares several genes in common with those typically induced in $R$-gene-mediated resistance. Genes encoding PR proteins are often triggered during the early response to pathogen attack and are considered as a signature of the HR. In our study, several classes of defenserelated genes were induced, including those encoding various $\mathrm{PR}$ proteins and phenylpropanoid enzymes, which were also found in wheat cells undergoing HR cell death (Michel et al. 2006) as well as the HR in other pathosystems (Foster-Hartnett et al. 2007; Rinaldi et al. 2007; Samac and Graham 2007). Taken together, the response conditioned by Lr34 is reminiscent of some components of HR-type resistance but without the accompanying localized cell death. In addition, based on differences in gene expression in TcLr34 relative to Tc at both 3 and 7 dpi, the resistance response associated with $L r 34$ appears to occur over a relatively long period of time compared with typical HR-mediated resistance, which can occur within hours of pathogen application in some pathosystems (Caldo et al. 2006).

Interestingly, few genes differentially expressed at 3 dpi in TcLr34 were also found at $7 \mathrm{dpi}$ in TcLr34 (Fig. 2). This implies that, at $7 \mathrm{dpi}$, the response conditioned by Lr34 becomes distinct from the response at $3 \mathrm{dpi}$. Further, because only one differentially expressed gene was identified in common between 7-dpi Tc and 7-dpi TcLr34 (Fig. 2), the 7-dpi TcLr34 resistance response remains distinct from a susceptible response. The approximately 1-week delay in pustule formation in TcLr34 compared with Tc further supports this contention (Fig. 1).

\section{Multiple energy-producing responses support $L$ r34-mediated resistance.}

There has been sustained interest in defense-related gene products as they relate to plant disease resistance. Much less attention has been paid to the role of metabolic pathways needed to provide energy to mount active defense responses, which represent a major reprogramming of cell metabolism. In this study, the top $10 \%$ upregulated genes in Lr34 at 3 and 7 dpi are classified as defense-related. At 3 dpi, these genes had fold-regulation differences ranging from approximately 10fold to over 60 -fold. In contrast, upregulation ranged from 5fold to just under 11 -fold at $7 \mathrm{dpi}$. This high level of induced gene expression at 3 dpi imposes an additional energetic demand on the plant, particularly in the absence of an HR.

Taken together, the observed upregulation of genes coding for rate-limiting enzymes of the TCA cycle, in tandem with those encoding enzymes at regulatory points in glycolysis, the enzyme PDH, the PDH bypass, $\beta$-oxidation, CoA biosynthesis, as well as the GABA shunt suggest that Lr34-mediated resistance is an extremely energy-intensive process (Table 3). This resistance places an increased energy demand on cells that is met both by upregulating glycolysis and the TCA and by recruiting alternative metabolic pathways to support ATP, NADH, and $\mathrm{FADH}_{2}$ levels needed to maintain the Lr34-mediated resistance response.

The TCA cycle is a central metabolic pathway for aerobic processes and is responsible for a major portion of carbohydrate, fatty acid, and amino acid oxidation that produces energy and reduces power, ultimately yielding 15 ATP equivalents per pyruvate molecule (Fernie et al. 2004). We identified differential expression of genes encoding enzymes at two of the three flux control points in the TCA cycle. Transcripts encoding citrate synthase (CS) and $\alpha$-ketoglutarate dehydrogenase $(\alpha-\mathrm{KGDH})$ were more abundant in pathogen-inoculated TcLr34 plants at 3 dpi (Table 3). Both of these enzymes are considered rate-limiting and control the flux through this primary cycle under normal conditions (Strumilo 2005; Wiegand and Remington 1986), and our results suggest a demand for heightened carbon flux through the TCA to produce more energy and a concomitant change in gene expression to accommodate the demand.

Genes encoding enzymes of glycolysis were upregulated in TcLr34 at 3 dpi (Table 3 ). The enzyme PFK is the main regulator of glycolysis, catalyzing the irreversible conversion of fructose 6-phosphate to fructose 1,6-bisphosphate, consuming one mole of ATP in the process. Likewise, PPi-PFK catalyzes the same process but in an ATP-independent manner (Mertens et al. 1990). The specific induction of both PFK and PPi-PFK suggests that the $L r 34$ response to $P$. triticina leads to increased levels of these two key enzymes to increase flux through glycolysis to generate more pyruvate. This pyruvate has several fates (Plaxton 1996). In aerobic respiration, oxidative metabolism by PDH converts pyruvate to acetyl-CoA that then enters the TCA cycle. Pyruvate can also be interconverted by LDH to lactate and $\mathrm{NAD}^{+}$(Fig. 4). Whereas lactate production is often considered to be associated with anaerobic metabolism, $L d h$ transcripts or LDH activity has often been found in oxygenated plant tissues (Germain et al. 1997; O'Carra and Mulcahy 1996; Shi et al. 2008). The NAD ${ }^{+}$produced by LDH can support glycolysis, which may explain the upregulation of $L d h$ observed in this study. Finally, pyruvate can be converted into acetaldehyde and $\mathrm{CO}_{2}$ by the enzyme PDC. Tadege and associates (1999) proposed the "PDH bypass," whereby acetaldehyde produced by PDC is oxidized to acetate and then converted to acetyl-CoA by the enzymes ALDH and ACS, respectively, with the resulting acetyl-CoA entering the TCA cycle (Fig. 4). Upregulation of genes for the PDH bypass in our study supports a role for the PDH bypass as an energy-producing component of Lr34-mediated resistance. Indeed, the PDH bypass was recently described as critical for bolstering the high energy requirement of growing pollen tubes (Gass et al. 2005).

CoA is a precursor for the synthesis of acetyl-CoA (together with pyruvate) that enters the TCA cycle (Fig. 4). For each acetyl-CoA that enters the TCA cycle, one GTP, one $\mathrm{FADH}_{2}$, and three NADH are produced, with the $\mathrm{FADH}_{2}$ and NADH subsequently reoxidized through oxidative phosphorylation to form ATP. The specific upregulation of genes encoding CoA$\mathrm{A}$, the first and rate-limiting enzymatic step in the CoA synthesis pathway, and CoA-D (Rubio et al. 2006), together with upregulation of genes encoding enzymes at various other flux control points in primary metabolic pathways, indicates a need for additional CoA to support increased energy production in the early stages of Lr34-mediated resistance (Table 3), concordant with observed upregulation of genes in the TCA and glycolysis.

CoA is also a cofactor in the $\beta$-oxidation cycle, which mediates degradation of fatty acids to produce acetyl-CoA that can enter the TCA (Lynen 1955). The upregulation of three of the four genes in the $\beta$-oxidation pathway is significant because the cycle is highly exergonic, generating one $\mathrm{NADH}$, one 
$\mathrm{FADH}_{2}$, and one acetyl-CoA for each round of the cycle (Lynen 1955). Therefore, the complete oxidation of a fatty acid molecule generates a significant amount of ATP through the oxidative phosphorylation of NADH and $\mathrm{FADH}_{2}$ and oxidation of acetyl-CoA produced after it enters the TCA cycle. As for previous pathways with upregulated genes, this result supports a heightened demand for carbon flux through the TCA cycle, with the acetyl CoA to support this metabolic response deriving from multiple sources.

The GABA shunt, induced in Lr34-mediated resistance at 3 dpi (Table 3), produces succinate using either glutamate or $\alpha$ ketoglutarate as substrates (Fig. 4). This pathway is induced in response to many stress conditions (Brown and Shelp 1997). Although GABA has been recognized as a signal molecule (Shelp et al. 2006), the GABA shunt also may support the energy demand of Lr34-mediated resistance. First, energetically demanding conditions can produce pyruvate in excess of the rate at which PDH can convert it to acetyl CoA. The GABA shunt provides a second entry point for pyruvate into the TCA cycle through its involvement in the conversion of GABA to succinic semialdehyde which then is converted to the TCA intermediate succinate. This provides a mechanism both to manage excess pyruvate and to employ it for energy production. Second, the TCA enzymes aconitase, succinyl-CoA ligase, and $\alpha$-ketoglutarate dehydrogenase are inactivated under oxidative stress conditions (Sweetlove et al. 2002; Tretter and Adam-Vizi, 2000). If these enzymes are inhibited, the GABA shunt can maintain carbon flux through the TCA cycle by circumventing this series of enzymes and providing succinate to a later step in the TCA, with NADH generation unaltered (Tretter and Adam-Vizi 2000).

This study provides evidence that $L r 34$-mediated resistance involves the coordinated recruitment of a well-defined set of metabolic pathways to support heightened energy production needed to sustain cells during earlier stages of the Lr34 resistance response. However, such responses are not maintained at later stages of the resistance response. Indeed, none of the upregulated genes in glycolysis, the PDH bypass, $\beta$-oxidation, acetyl-CoA synthesis, TCA cycle, or the GABA shunt identified at 3 dpi were upregulated in TcLr34 at 7 dpi. This change in gene expression between 3 and 7 dpi suggests that the high energy demand associated with Lr34 cannot be maintained over a prolonged period of time. Alternatively, because it has been speculated that obligate biotrophic pathogens may actively suppress host defense reactions (Bushnell and Rowell 1981; Panstruga 2003), it is also possible that the pathogen is responsible for suppression of these metabolism-related genes in TcLr34 by 7 dpi. The decay of the broad array of energy production-related metabolic responses by the $7 \mathrm{dpi}$ timepoint may explain why Lr34 ultimately fails to inhibit the pathogen fully. Further, the results of this study demonstrate that racenonspecific leaf rust resistance conferred by $\operatorname{Lr} 34$ is associated with transcriptional changes distinct from a typical race-specific response. The early recruitment of additional metabolic pathways to bolster energy production, and the subsequent loss of these pathways as sources of energy to supplement respiration over time, provides an explanation for phenotypic features of race-nonspecific resistance associated with $L r 34$, including the latent period.

\section{MATERIALS AND METHODS}

\section{Plant and fungal material.}

Wheat (T. aestivum) cvs. Thatcher (Tc), near-isogenic Thatcher $L r l$ (TcLrl, RL6003) with the $L r l$ resistance gene, and near-isogenic Thatcher Lr34 (TcLr34, RL6058) with the Lr34 resistance gene were used in this study. Leaf rust (P. triticina) race 1 urediniospores (virulence phenotype BBB) (Long and Kolmer 1989) were increased on seedlings of Little Club wheat and stored at $4^{\circ} \mathrm{C}$ until use (within a week of harvest).

\section{Plant growth.}

Seed of each genotype were stratified on wet filter paper for 4 days, and then planted three to a pot in 6-in. round plastic pots (Belden Plastics, Roseville, MN, U.S.A.) filled with a potting mixture of field soil, compost, and sand. Nutricote 100day slow-release $13-13-13$ pellets $(20 \mathrm{~g})$ with micronutrients (SunGro, Vancouver, British Columbia, Canada) were placed into each pot. Pots were placed in a growth chamber (Conviron PGW36; Conviron, Winnipeg, Canada) initially set at $18^{\circ} \mathrm{C}$, day and $16^{\circ} \mathrm{C}$, night, with a 16 -h day, 8 -h night light regime, with a photon flux of $572 \mu \mathrm{E}$. The pots were laid out in a split plot with three replications. Genotypes were the main effect and the subplots were treatments (mock inoculated or pathogen inoculated). For each rep, six pots (three plants per pot) were planted per genotype. Pots were watered on an as-needed basis. After 1 month, the temperature was dropped to 15 and $13^{\circ} \mathrm{C}$, day and night temperatures, respectively, to help ensure synchronized flowering, and subsequently the temperature was gradually increased to 20 and $17^{\circ} \mathrm{C}$ (day and night, respectively) $\left(16\right.$ and $14^{\circ} \mathrm{C} 9$ days after setting to 15 and $13^{\circ} \mathrm{C}, 17$ and $15^{\circ} \mathrm{C}$ 2 days later, 18 and $16^{\circ} \mathrm{C} 2$ days later, and 20 and $17^{\circ} \mathrm{C} 9$ days later). Pots were also watered thoroughly with a fertilizer solution (Peters 20-20-20 soluble fertilizer at $1.86 \mathrm{~g} \mathrm{liter}^{-1}$ ) 3 and 8 weeks after planting, and with a more dilute solution $(0.62 \mathrm{~g}$ liter ${ }^{-1}$ ) of the same soluble fertilizer 6 weeks after planting. Two months after sowing, plants were ready for inoculation.

\section{Plant disease inoculations.}

Tillers at anthesis ( \pm 1 day) on each plant were tagged prior to inoculation. Flag leaves of each tiller were individually inoculated on the adaxial face either with Soltrol 170 oil alone or with a suspension of P. triticina spores in Soltrol 170 oil (18 $\mathrm{mg}$ of spores per milliliter of oil). Inoculations employed two passes across the leaf surface with an atomizer nozzle. Spore densities applied to leaves were determined by inoculating six microscope slides during the course of the inoculations and then counting the number of spores in a defined area (2.67 $\mathrm{mm}^{1}$ ) on each slide under a microscope. Using this method, the average spore density on inoculated leaf surfaces was determined to be 592 spores $\mathrm{cm}^{-1}$. Spore germination was assessed by spraying water agar plates lightly with inoculum and then determining the percentage of spores that had germinated after $4 \mathrm{~h}$. By this method, $75 \%$ of spores had germinated (germination tube evident), while a significant portion of the other spores were oblong in shape, indicating that they were in the early process of germinating.

After allowing oil to dry off of leaf surfaces for $1.5 \mathrm{~h}$, pots were placed in mist chambers (one rep per chamber) and subjected to $30 \mathrm{~min}$ initial misting. A mist cycle of $30 \mathrm{~min} \mathrm{mist} / 4$ min no mist was then employed for $3 \mathrm{~h}$, followed by a mist cycle of $10 \mathrm{~min}$ on/10 min off for $5 \mathrm{~h}$, and finally a mist regime of $6 \mathrm{~min}$ on/10 $\mathrm{min}$ off for $10 \mathrm{~h} 45 \mathrm{~min}$. The temperature in the mist chamber during the mist period was $21 \pm 1^{\circ} \mathrm{C}$. Plant were then removed from the mist chambers, allowed to dry, and placed back into the growth chamber.

Tissue harvest, RNA extraction, and microarray analysis.

At both 3 and $7 \mathrm{dpi}$, seven to nine mock- or pathogen-inoculated flag leaves from each replicate-treatment combination were harvested, placed in liquid $\mathrm{N}_{2}$, and then moved to a $-80^{\circ} \mathrm{C}$ freezer until RNA extractions were performed for use in microarray analyses. A final set of leaves was similarly harvested at 14 days after they served to monitor pathogen proliferation 
during the experiment. In this case, six to nine leaves were harvested across replicates and bulked for RNA isolation and for use in monitoring of pathogen biomass.

RNA extraction, cRNA probe preparation, and microarray hybridization to Affymetrix GeneChip Wheat Genome Arrays and data acquisition was performed as reported by Cho and associates (2006). A description of the GeneChip wheat genome array is available at the manufacturer's website.

\section{Data analysis.}

We normalized $P$. triticina- and mock-inoculated data together for each genotype at each timepoint. Comparisons between mock-inoculated controls and pathogen-inoculated plants on a per-genotype basis allowed the identification of genes specifically induced by $P$. triticina without Ltn-related gene expression interference. In addition, comparisons within a single genetic background negate any between-genotype background variation that may inadvertently identify genes not associated with plant defense.

Data analysis was conducted using the Expressionist software (version Pro 3.1; Genedata AG, CH-4016 Basel, Switzerland). A description of the major analysis tools of Expressionist has previously been described (Boddu et al. 2006; Cho et al. 2006; Viemann et al. 2004). The raw probe-level hybridization data (CEL files) for each of the $P$. triticina-inoculated or mockinoculated replications for each genotype per timepoint were loaded into the Expressionist Refiner module. High data quality was assured by defect detection, corner noise detection, outlier area detection, and $3^{\prime} / 5^{\prime}$ ratio of housekeeping gene assessments. The probe set values were then condensed using the MAS 5.0 algorithm (Affymetrix) within the Expressionist Refiner Array module without any additional correction or masking manipulation. Within the Expressionist Analyst module, the MAS 5.0 signal data were natural-log transformed and normalized to a median target intensity of 500 for each chip without any subsequent normalization to preserve GeneChip independence among replications as described by Caldo and associates (2004).

Using the Analyst internal quality setting of $P=0.04$, probe sets were required to pass a Student's $t$ test $(P$ value $\leq 0.001)$ and have a mean fold change of $\geq 2.0$ to be called differentially expressed. To complement statistical tests, the Analyst module contains a Present/Absent search activity to identify probe sets predominantly present in one treatment but absent in another. Probe sets with absent values cannot be identified in a $t$ test but may still be biologically relevant; therefore, we used this search activity to identify probe sets that were present in all three replications from one treatment (e.g., $P$. triticina-inoculated) but absent in all three replications of the other treatment (e.g., mock-inoculated) in an approach essentially as described by Viemann and associates (2004). Briefly, to quantify the expression values of probe sets deemed absent, normalized raw probe set expression values were extracted by adjusting the Analyst internal quality setting to $P=1.0$, which provided a value for each transcript regardless of the level of signal. Expression values were subsequently subjected to a student's $t$ test $(P$ value $\leq 0.001)$ and mean fold change of $\geq 2.0$ to be considered differentially expressed. In all cases, the $P$ values for each test were converted to $q$ values using the method described by Storey and Tibshirani (2003) to estimate the FDR. Microarray data were deposited at the National Center for Biotechnology Information (NCBI) Gene Expression Omnibus database under the accession number GSE9915.

We assumed that each probe set was equivalent to a gene transcript. In several cases, differentially expressed probe sets quantified expression of the same gene. These redundant probe sets were manually removed from gene lists. Genes were then assigned to broad functional classes (metabolism/structure/ maintenance, defense/stress, signal transduction, transcription, transport, or unclassified) or listed as "no annotation available" based on annotation provided by HarvEST Wheat1 chip version 1.51 (Close et al. 2007). Genes were annotated based on the top hit with an $e$ value $<10^{-10}$. In cases where top hits were to hypothetical proteins or where no annotation was available, these genes were subjected to BLASTN or BLASTX searches based on the consensus sequence of the probe sets against the nonredundant (nr) protein sequence database at the NCBI, The Institute for Genomic Research (TIGR) Rice database, or the TIGR A. thaliana database to gain any additional information on gene function. GO terms for biological and molecular function (Ashburner et al. 2000) were obtained by querying the UniProt Protein Knowledgebase with protein IDs from HarvEST.

\section{qPCR analysis.}

qPCR was carried out using the Applied Biosystems 7000 Real-Time PCR system. Specific primers for each gene selected were designed using Primer Express software (version 3.0; Applied Biosystems, Foster City, CA, U.S.A.) or Vector NTI Advance 10 software (version 10.1.1; Invitrogen, Carlsbad, CA, U.S.A.). The wheat 18S rRNA gene was used as an internal reference for relative quantification analyses using qPCR primers previously reported (Scofield et al. 2005). The $P$. triticina internal transcribed spacer region of the 18S rRNA gene was used to measure fungal biomass using primers provided by L. Szabo (United States Department of AgricultureAgricultural Research Service, Cereal Disease Laboratory, St. Paul, MN).

For transcript quantification studies, a cDNA template prepared from pooled total RNA from the biological replicates used for microarray analysis was used. qPCR reactions were conducted in a $25-\mu 1$ volume in triplicate using the iTaq SYBR Green Supermix system (Bio-Rad, Hercules, CA, U.S.A.). qPCR conditions were as follows: $95^{\circ} \mathrm{C}$ for $2 \mathrm{~min}$, followed by 40 cycles of $95^{\circ} \mathrm{C}$ for $15 \mathrm{~s}$ and $60^{\circ} \mathrm{C}$ for $45 \mathrm{~s}$. The quantification of gene expression and fungal biomass determination was performed using the comparative $\mathrm{C}_{\mathrm{T}}$ method $\left(\Delta \Delta \mathrm{C}_{\mathrm{T}}\right)$.

\section{LITERATURE CITED}

Abramovitch, R. B., and Martin, G. B. 2004. Strategies used by bacterial pathogens to suppress plant defenses. Curr. Opin. Plant Biol. 7:356-364.

Ashburner, M., Ball, C. A., Blake, J. A., Botstein, D., Butler, H., Cherry, J. M., Davis, A. P., Dolinski, K., Dwight, S. S., Eppig, J. T., Harris, M. A., Hil, D. P., Issel-Tarver, L., Kasarskis, A., Lewis, S., Matese, J. C., Richardson, J. E., Ringwald, M., Rubin, G. M., and Sherlock, G. 2000. Gene ontology: Tool for the unification of biology. Nat. Genet. 25:2529.

Ausubel, F. M. 2005. Are innate immune signaling pathways in plants and animals conserved? Nat. Immunol. 6:973-979.

Boddu, J., Cho, S., Kruger, W. M., and Muehlbauer, G. J. 2006. Transcriptome analysis of the Barley-Fusarium graminearum interaction. Mol. Plant-Microbe Interact. 19:407-417.

Bolton, M. D., Kolmer, J. A., and Garvin, D. F. 2008. Wheat leaf rust caused by Puccinia triticina. Mol. Plant Pathol. 9:563-575.

Brown, A. W., and Shelp, B. J. 1997. The metabolism and function of $\gamma$ aminobutyric acid. Plant Physiol. 115:1-5.

Bushnell, W. R., and Rowell, J. B. 1981. Suppressors of defense reactions: A model for roles in specificity. Phytopathology 71:1012-1014.

Caldo, R. A., Nettleton, D., and Wise, R. P. 2004. Interaction-dependent gene expression in Mla-specified response to barley powdery mildew. Plant Cell 16:2514-1528.

Caldo, R. A., Nettleton, D., Peng, J., and Wise, R. P. 2006. Stage-specific suppression of basal defense discriminates barley plants containing fastand delayed-acting Mla powdery mildew resistance alleles. Mol. PlantMicrobe Interact. 19:939-947.

Cho, S., Garvin, D. F., and Muehlbauer, G. J. 2006. Transcriptome analysis and physical mapping of barley genes in wheat-barley chromosome addition lines. Genetics 172:1277-1285.

Close, T. J., Wanamaker, S., Roose, M. L., and Lyon, M. 2007. HarvEST: 
An EST database and viewing software. Methods Mol. Biol. 406:161178

Cloutier, S., McCallum, B. D., Loutre, C., Banks, T. W., Wicker, T., Feuillet, C., Keller, B., and Jordan, M. C. 2007. Leaf rust resistance gene $\mathrm{Lrl}$, isolated from bread wheat (Triticum aestivum L.) is a member of the large psr567 gene family. Plant Mol. Biol. 65:93-106.

Dangl, J. L. 2007. Nibbling at the plant cell nucleus. Science 315:10881089.

Danna, C. H., Sacco, F., Ingala, L. R., Saione, H. A., and Ugalde, R. A 2002. Cloning and mapping of genes involved in wheat-leaf rust interaction through gene-expression analysis using chromosome-deleted near-isogenic wheat lines. Theor. Appl. Genet. 105:972-979.

Drijepondt, S. C., and Pretorius, Z. A. 1989. Greenhouse evaluation of adult-plant resistance conferred by the gene Lr34 to leaf rust of wheat. Plant Dis. 73:669-671.

Dyck, P. L. 1987. The association of a gene for leaf rust resistance with the chromosome 7D suppressor of stem rust resistance in common wheat. Genome 29:467-469.

Dyck, P. L. 1991. Genetics of adult-plant rust resistance in 'Chinese Spring' and 'Sturdy' wheats. Crop Sci. 24:309-311.

Dyck, P. L. 1994. Genetics of resistance to leaf rust and stem rust on wheat. Annu. Wheat Newsl. 40:79-80.

Dyck, P. L., Samborski, D. J., and Anderson, R. G. 1966. Inheritance of adult-plant leaf rust resistance derived from the common wheat varieties Exchange and Frontana. Can. J. Genet. Cytol. 8:665-671.

Fernie, A. R., Carrari, F., and Sweetlove, L. J. 2004. Respiratory metabolism: Glycolysis, the TCA cycle and mitochondrial electron transport. Curr. Opin. Plant Biol. 7:254-261.

Feuillet, C., Travella, S., Stein, N., Albar, L., Nublat, L., and Keller, B. 2003. Map-based isolation of the leaf rust disease resistance gene $\mathrm{Lr} 10$ from the hexaploid wheat (Triticum aestivum L.) genome. Proc. Natl. Acad. Sci. U.S.A. 100:15253-15258

Foster-Hartnett, D., Danesh, D., Penuela, S., Sharopova, N., Endre, G., Vandenbosch, K. A., Young, N. D., and Samac, D. A. 2007. Molecular and cytological responses of Medicago truncatula to Erysiphe pisi. Mol. Plant Pathol. 8:307-319.

Gass, N., Glagotskaia, T., Mellema, S., Stuurman, J., Barone, M., Mandel, T., Roessner-Tunali, U., and Kuhlemeier, C. 2005. Pyruvate decarboxylase provides growing pollen tubes with a competitive advantage in Petunia. Plant Cell 17:2355-2368.

Germain, V., Raymond, P., and Ricard, B. 1997. Differential expression of two tomato lactate dehydrogenase genes in response to oxygen deficit. Plant Mol. Biol. 35:711-721.

Gjetting, T., Hagedorn, P. H., Schweizer, P., Thordal-Christensen, H., Carver, T. L. W., and Lyngkjær, M. F. 2007. Single-cell transcript profiling of barley attacked by the powdery mildew fungus. Mol. PlantMicrobe Interact. 20:235-246.

Herrmann, K. M., and Weaver, L. M. 1999. The shikimate pathway. Annu. Rev. Plant Physiol. Plant Mol. Biol. 50:473-503.

Hill-Ambroz, K., Webb, C. A., Matthews, A. R., Li, W., Gill, B. S., and Fellers, J. P. 2006. Expression analysis and physical mapping of a cDNA library of Fusarium head blight infected wheat spikes. Crop Sci. 46:S15-S26

Huang, L., Brooks, S. A., Li, W., Fellers, J. P., Trick, H. N., and Gill, B. S. 2003. Map-based cloning of leaf rust resistance gene $\operatorname{Lr} 21$ from the large and polyploidy genome of wheat. Genetics 164:655-664.

Hulbert, S. H., Bai, J., Fellers, J. P., Pacheco, M. G., and Bowden, R. L. 2007. Gene expression patterns in near isogenic lines for wheat rust resistance gene Lr34/Yr18. Phytopathology 97:1083-1093.

Hurkman, W. J., and Tanaka, C. K. 1996. Germin gene expression is induced in wheat leaves by powdery mildew infection. Plant Physiol. 111:735-739.

Jones, J. D. J., and Dangl, J. L. 2006. The plant immune system. Nature 444:323-329.

Kang, Z., and Buchenauer, H. 2000. Ultrastructural and immunocytochemical investigation of pathogen development and host resistant and susceptible wheat spikes infected by Fusarium culmorum. Physiol. Mol. Plant Pathol. 57:255-268.

Kim, G. M., Cunha, L., McFall, A. J., Belkhadir, Y., Debroy, S., Dang1, J. L., and Mackey, D. 2005. Two Pseudomonas syringae Type III effectors inhibit RIN4-regulated basal defense in Arabidopsis. Cell 121:749-759.

Kolmer, J. A. 1996. Genetics of resistance to wheat leaf rust. Annu. Rev. Phytopathol. 34:435-455.

Kolmer, J. A. 2005. Tracking wheat rust on a continental scale. Curr. Opin. Plant Biol. 8:441-449.

Kolmer, J. A., and Oelke, L. M. 2006. Genetics of leaf rust resistance in the spring wheat cultivars Ivan and Knudson. Can. J. Plant Pathol. 28:223-229.

Kong, L., Anderson, J. M., and Ohm, H. W. 2005. Induction of wheat defense and stress-related genes in response to Fusarium graminearum. Genome 48:29-40.

Kruger, W. M., Szabo, L. J., and Zeyen, R. J. 2003. Transcription of the defense response genes chitinase IIb, PAL and Peroxidase is induced by the barley powdery mildew fungus and is only indirectly modulated by R genes. Physiol. Mol. Plant Pathol. 63:167-178.

Li, X., Hou, J., Bai, K., Yang, X., Lin, J., Li, Z., and Kuang, T. 2004. Activity and distribution of carbonic anhydrase in leaf and ear parts of wheat (Triticum aestivum L.). Plant Sci. 166:627-632.

Long, D. L., and Kolmer, J. A. 1989. A North American system of nomenclature for Puccinia recondita f. sp. tritici. Phytopathology 79:525-529.

Lynen, F. 1955. Lipide metabolism. Annu. Rev. Biochem. 24:653-688.

Mano, J., Belles-Boix, E., Babiychuk, E., Inze, D., Torii, Y., Hiraoka, E., Takimoto, K., Slooten, L., Asada, K., and Kushnir, S. 2005. Protection against photooxidative injury of tobacco leaves by 2 -alkenal reductase. Detoxification of lipid peroxide-derived reactive carbonyls. Plant Physiol. 139:1773-1783.

Martín, M., León, J., Dammann, C., Albar, J.-P., Griffiths, G., and Serrano, J. J. S. 1999. Antisense-mediated depletion of potato leaf $\omega 3$ fatty acid desaturase lowers linolenic acid content and reduces gene activation in response to wounding. Eur. J. Biochem. 262:283-290.

McIntosh, R. A., Wellings, C. R., and Park, R. F. 1995. Wheat Rusts: An Atlas of Resistance Genes. Kluwer Academic Publishers, Dordrecht, The Netherlands.

Mertens, E., Larondelle, Y., and Hers, H.-G. 1990. Induction of pyrophosphate:fructose 6-phosphate 1-phosphotransferase by anoxia in rice seedlings. Plant Physiol. 93:584-587.

Michel, K., Abderhalden, O., Bruggmann, R., and Dudler, R. 2006. Transcriptional changes in powdery mildew infected wheat and Arabidopsis leaves undergoing syringolin-triggered hypersensitive cell death at infection sites. Plant Mol. Biol. 62:561-578.

Noctor, G., Queval, G., and Gakière, B. 2006. NAD(P) synthesis and pyridine nucleotide cycling in plants and their potential importance in stress conditions. J. Exp. Bot. 57:1603-1620.

Nürnberger, T., Brunner, F., Kemmerling, B., and Piater, L. 2004. Innate immunity in plants and animals: Striking similarities and obvious differences. Immunol. Rev. 198:249-266.

O'Carra, P., and Mulcahy, O. 1996. Lactate dehydrogenase in plants: Distribution and function. Phytochemistry 42:581-587.

Oelke, L. M., and Kolmer, J. A. 2005. Genetics of leaf rust resistance in spring wheat cultivars Alsen and Norm. Phytopathology 95:773-778.

Ordoñez, M. E., and Kolmer, J. A. 2007. Virulence phenotypes of a worldwide collection of Puccinia triticina from durum wheat. Phytopathology 97:344-351.

Panstruga, R 2003. Establishing compatibility between plants and obligate biotrophic pathogens. Curr. Opin. Plant Biol. 6:320-326.

Plaxton, W. C. 1996. The organization and regulation of plant glycolysis. Annu. Rev. Plant Physiol. Plant Mol. Biol. 47:185-214.

Pritsch, C., Vance, C. P., Bushnell, W. R., Somers, D. A., Hohn, T. M., and Muehlbauer, G. J. 2001. Systemic expression of defense response genes in wheat spikes as a response to Fusarium graminearum infection. Physiol. Mol. Plant Pathol. 58:1-12.

Rampitsch, C., Bykova, N. V., McCallum, B., Beimcik, E., and Ens, W. 2006. Analysis of the wheat and Puccinia triticina (leaf rust) proteomes during a susceptible host-pathogen interaction. Proteomics 6:18971907

Rinaldi, C., Kohler, A., Frey, P., Duchaussoy, F., Ningre, N., Couloux, A., Wincker, P., Thiec, L., Fluch, S., Martin, F., and Duplessis, S. 2007. Transcript profiling of poplar leaves upon infection with compatible and incompatible strains of foliar rust Melampsora larici-populina. Plant Physiol. 144:347-366.

Rubiales, D., and Niks, R. E. 1995. Characterization of Lr34, a major gene conferring nonhypersensitive resistance to wheat leaf rust. Plant Dis. 79:1208-1212.

Rubio, S., Larson, T. R., Gonzalez-Guzman, M., Alejandro, A., Graham, I. A., Serrano, R., and Rodriguez, P. L. 2006. An Arabidopsis mutant impaired in coenzyme A biosynthesis is sugar dependent for seeding establishment. Plant Physiol. 140:830-843.

Samac, D. A., and Graham, M. A. 2007. Recent advances in legumemicrobe interactions: Recognition, defense response, and symbiosis from a genomic perspective. Plant Physiol. 144:582-587.

Scofield, S. R., Huang, L., Brandt, A. S., and Gill, B. S. 2005. Development of a virus-induced gene-silencing system for hexaploid wheat and its use in functional analysis of the Lr21-mediated leaf rust resistance pathway. Plant Physiol. 138:2165-2173.

Shelp, B. J., Bown, A. W., and Faure, D. 2006. Extracellular $\gamma$-aminobutyrate mediates communication between plants and other organisms. Plant Physiol. 142:1350-1352.

Shi, K., Ding, X. T, Dong, D. K., Zhou, Y. H., and Yu, J. Q. 2008. Putrescine enhancement of tolerance to root-zone hypoxia in Cucumis sati- 
vus: A role for increased nitrate reduction. Funct. Plant Biol. 35:337345

Shojima, S., Nishizawa, N. K., Fushiya, S., Irifune, T., and Mori, S. 1990. Biosynthesis of phytosiderophores. In vitro biosynthesis of $2^{\prime}$-deoxymugineic acid from L-methionine and nicotianamine. Plant Physiol 93:1497-1503.

Singh, R. P. 1992a. Association between gene Lr34 for leaf rust resistance and leaf tip necrosis in wheat. Crop Sci. 32:874-878.

Singh, R. P. 1992b. Genetic association of leaf rust resistance gene Lr34 with adult plant resistance to stripe rust in bread wheat. Phytopathology 82:835-838.

Singh, R. P. 1993. Genetic association of gene $B d v 1$ for tolerance to barley yellow dwarf virus with genes $\operatorname{Lr} 34$ and $\mathrm{Yr} 18$ for adult plant resistance to rusts in bread wheat. Plant Dis. 77:1103-1106.

Singh, R. P., and Gupta, A. K. 1992. Expression of wheat leaf rust resistance gene Lr34 in seedlings and adult plants. Plant Dis. 76:489-491.

Singh, R. P., and Huerta-Espino, J. 2003. Effect of leaf rust resistance gene Lr34 on components of slow rusting at seven growth stages in wheat. Euphytica 129:371-376.

Singh, B. K., and Shaner, D. L. 1995. Biosynthesis of branched chain amino acids: From test tube to field. Plant Cell 7:935-944.

Spielmeyer, W., McIntosh, R. A., Kolmer, J., and Lagudah, E. S. 2005. Powdery mildew resistance and $\mathrm{Lr} 34 / \mathrm{Yr} 18$ genes for durable resistance to leaf and stripe rust cosegregate at a locus on the short arm of chromosome 7D of wheat. Theor. Appl. Genet. 111:731-735.

Storey, J. D., and Tibshirani, R. 2003. Statistical significance for genomewide studies. Proc. Natl. Acad. Sci. U.S.A. 100:9440-9445.

Strumilo, S. 2005. Short-term regulation of the $\alpha$-ketoglutarate dehydrogenase complex by energy-linked and some other effectors. Biochemistry (Moscow) 70:726-729.

Sweetlove, L. J., Heazlewood, J. L., Holtzapffel, R., Day, D. A., Leaver, C. J., and Millar, A.H. 2002. The impact of oxidative stress on Arabidopsis mitochondria. Plant J. 32:891-904.

Tadege, M., Dupuis, I., and Kuhlemeier, C. 1999. Ethanolic fermentation: New functions for an old pathway. Trends Plant Sci. 4:320-325.
Thara, V. K., Fellers, J. P., and Zhou, J-M. 2003. In planta induced genes of Puccinia triticina. Mol. Plant Pathol. 4:51-56.

Tolbert, N. E. 1981. Metabolic pathways in peroxisomes and glyoxysomes. Annu. Rev. Biochem. 50:133-157.

Tretter, L., and Adam-Vizi, V. 2000. Inhibition of Krebs cycle enzymes by hydrogen peroxide: A key role of $\alpha$-ketoglutarate dehydrogenase in limiting NADH production under oxidative stress. J. Neurosci. 20:8972-8979.

Van Baarlen, P., Van Esse, H. P., Siezen, R. J., and Thomma, B. P. H. J. 2007. Challenges in plant cellular pathway reconstruction based on gene expression profiling. Trends Plant Sci. 13:44-50.

Viemann, D., Goebeler, M., Schmid, S., Klimmek, K., Sorg, C., Ludwig, S., and Roth, J. 2004. Transcriptional profiling of IKK2/NF-KB- and p38 MAP kinase-dependent gene expression in TNF- $\alpha$-stimulated primary human endothelial cells. Blood 103:3365-3373.

Webb, C. A., and Fellers, J. P. 2006. Cereal rust fungi genomics and the pursuit of virulence and avirulence factors. FEMS (Fed. Eur. Microbiol. Soc.) Microbiol. Lett. 264:1-7.

Wiegand, G., and Remington, S. J. 1986. Citrate synthase: Structure, control, and mechanism. Annu. Rev. Biophys. Biophys. Chem. 15:97-117.

Zhang, L., Meakin, H., and Dickinson, M. 2003. Isolation of genes expressed during compatible interactions between leaf rust (Puccinia triticina) and wheat using cDNA-AFLP. Mol. Plant Pathol. 4:469-477.

\section{AUTHOR-RECOMMENDED INTERNET RESOURCES}

Affymetrix GeneChip database: www.affymetrix.com/index.affx Affymetrix technical documentation: www.affymetrix.com/support/technical/whitepapers.affx

HarvEST database: harvest.ucr.edu

KOMUGI Integrated Wheat Science database catalogue of gene symbols: www.shigen.nig.ac.jp/wheat/komugi/genes/symbolClassList.jsp

NCBI Gene Expression Omnibus: www.ncbi.nlm.nih.gov/geo

UniProt Protein Knowledgebase: www.uniprot.org 